bioRxiv preprint doi: https://doi org/10.1101/2021.03.27.437306; this version posted March 28,2021 . The copyright holder for this preprint (which was not certified by peer review) is the author/funder, who has granted bioRxiv a license to display the preprint in perpetuity. It is made available under aCC-BY-NC-ND 4.0 International license.

\title{
The formation of the bacterial RNA polymerase-promoter open complex involves a branched pathway
}

Anssi M. M alinen ${ }^{1}$, Jacob Bakermans ${ }^{2}$, Emil Aalto-Setälä ${ }^{1}$, M artin Blessing ${ }^{2,3}$, David L.V. Bauer ${ }^{2}$, Olena Parilova ${ }^{1}$, Georgiy A. Belogurov ${ }^{1}$, David Dulin ${ }^{4,5}$, Achillefs N. Kapanidis ${ }^{2}$

Correspondence: Anssi M. Malinen (email: anssi.malinen@utu.fi) or Achillefs N. Kapanidis (email: achillefs.kapanidis@physics.ox.ac.uk)

1 Department of Life Technologies, University of Turku, Tykistökatu 6A, 20520 Turku, Finland

2 Biological Physics Research Group, Clarendon Laboratory, Department of Physics, University of Oxford, Parks Road, Oxford, OX1 3PU, UK.

3 Max Planck Institute for the Science of Light, Staudtstraße 2, 91058 Erlangen, Germany

4 Junior Research Group 2, Interdisciplinary Center for Clinical Research, Friedrich-AlexanderUniversity Erlangen-Nürnberg (FAU), Cauerstr. 3, 91058 Erlangen, Germany.

5 Department of Physics and Astronomy, and LaserLaB Amsterdam, Vrije Universiteit Amsterdam, De Boelelaan 1081, 1081 HV, Amsterdam, The Netherlands

\begin{abstract}
Abbreviations
Alternating laser excitation, ALEX; $\alpha C T D$, C-terminal domain of RNA polymerase $\alpha$-subunit; $\mathrm{Cl}$, confidence interval; Cor, corallopyronin A; cryo-electron microscopy, cryo-EM; E*, apparent FRET efficiency; FRET, fluorescence energy transfer; GL, gate loop in the RNAP $\beta$ subunit; HMM, Hidden Markov modelling; $L L$, lid loop in the RNAP $\beta^{\prime}$ subunit; $M y x$, myxopyronin $B$; $R L$, rudder loop in the RNAP $\beta$ ' subunit; RNAP, RNA polymerase; RPc, RNAP-promoter closed complex; $\mathrm{RP}_{i}$, RNAP-promoter intermediate complex; RPo, RNAP-promoter open complex; SD, standard deviation; SE, standard error.
\end{abstract}

\section{Abstract}

The expression of most bacterial genes commences with the binding of RNA polymerase (RNAP)- $\sigma^{70}$ holoenzyme to the promoter DNA. This initial RNAP-promoter closed complex undergoes a series of conformational changes, including the formation of a transcription bubble on the promoter and the loading of template DNA strand into the RNAP active site; these changes lead to the catalytically active open complex ( $\mathrm{RP}_{0}$ ) state. Recent cryo-electron microscopy studies have provided detailed structural insight on the RPo and putative intermediates on its formation pathway. Here, we employ singlemolecule fluorescence microscopy to interrogate the conformational dynamics and reaction kinetics during real-time $\mathrm{RP}_{0}$ formation. We find that the $\mathrm{RP}_{0}$ pathway is branched, generating $\mathrm{RP}_{0}$ complexes with different stabilities. The RNAP cleft loops, and especially the $\beta^{\prime}$ rudder, stabilise the transcription bubble. The RNAP interactions with the promoter upstream sequence (beyond -35) stimulate transcription bubble nucleation and tune the reaction path towards stable forms of the RPo. The mechanistic heterogeneity of the RPo pathway may be a prerequisite for its regulation since such heterogeneity allows the amplification of small promoter sequence or transcription-factor-dependent changes in the free energy profile of the RPo pathway to large differences in transcription efficiency. 
bioRxiv preprint doi: https://doi.org/10.1101/2021.03.27.437306; this version posted March 28,2021 . The copyright holder for this preprint (which was not certified by peer review) is the author/funder, who has granted bioRxiv a license to display the preprint in perpetuity. It is made available under aCC-BY-NC-ND 4.0 International license.

\section{Introduction}

Transcription initiation is the first and most regulated step in gene expression in all organisms. The expression of most bacterial genes commences with the binding of RNA polymerase (RNAP)- $\sigma^{70}$ holoenzyme to the promoter DNA (1). The initial RNAP-promoter closed complex (RPc) undergoes large conformational changes leading to a RNAP-promoter open complex (RPo), which is capable of RNA synthesis. These conformational changes are of paramount importance, since their modulation by promoter DNA sequence, protein transcription factors, and small-molecule ligands strongly affects the number of active open complex, and thus the transcription efficiency (2). Further, several antimicrobials, including clinically used drugs rifampicin (3)(4) and fidaxomicin (5), exert their effect by blocking RNAP from proceeding during a specific step of transcription initiation (6). However, despite substantial progress in defining the structural basis of transcription initiation mechanism (7)(8)(9)(10), the identity, sequence, and kinetics of conformational changes leading to RP 0 formation remain elusive.

At the initial step of the RPo formation pathway, the RNAP- $\sigma^{70}$ holoenzyme recognises the promoter by forming sequence-specific contacts with the -35 element, and sequence-independent contacts upstream from the -35 ("upstream sequence" ) as well as around the -10 element [reviewed in (2)(11)]. In this RPc state, the promoter remains fully double-stranded, but is bent by $\sim 17^{\circ}$ at the -10 element, thus positioning the downstream promoter DNA above the DNA-binding cleft of the RNAP (10). Studies using footprinting (12)(13)(14)(15), atomic force microscopy (16) and ensemble FRET (17) have indicated additional extensive bending and wrapping of the promoter upstream sequence (between the -35 element and -82); this bending, which is driven by the C-terminal domains of the two RNAP $\alpha$ subunits ( $\alpha$ CTDs) interacting with the promoter upstream, brings the upstream DNA to the RNAP surface, and strongly facilitates RPo complex formation (18)(14)(19).

The isomerisation of the $\mathrm{RP}_{c}$ towards $\mathrm{RP}_{0}$ complex begins with the flipping of non-template DNA (ntDNA) -11 conserved adenine base from the duplex DNA to a specific pocket in $\sigma^{70}(20)(21)$. The promoter melting then somehow propagates downstream until the full transcription bubble in the $\mathrm{RP}_{0}$ complex covers positions -11 to +2 (9). The bubble melting is coupled with the loading of downstream DNA duplex into the RNAP cleft, and the loading of single-stranded template DNA (tDNA) into the RNAP active site. Structural (9)(10) and biochemical (2) studies have identified several putative intermediates on the path from the $\mathrm{RP}_{\mathrm{c}}$ to $\mathrm{RP}_{0}$; however, the number and structural properties of the intermediates detected appear to heavily depend on the promoter sequence, transcription factors, and experimental conditions.

The mechanism discussed above describes the formation of a uniform RPo complex on a standard linear reaction pathway. A more complete description of the transcription initiation, however, needs to consider several studies that suggested that individual RPo molecules are not identical, and they instead differ in functional properties (22)(23)(24)(25). One of the most notable variation among RPo complexes is their tendency to perform abortive initiation, i.e., the premature release of short RNAs synthesised by promoter-bound RNAP [reviewed in (26)]. In fact, it has been estimated that $>50 \%$ of the $\mathrm{RP}_{0}$ complexes are permanently locked into the abortive initiation mode and cannot produce fulllength RNA (22)(23)(24)(25). The presence of at least two different RPo classes - one productive and one non-productive (abortive) - raises the possibility that the RPo pathway is also not linear, but instead branches to allow the formation of structurally and functionally different $\mathrm{RP}_{0}$ molecules. It has been further suggested that the ratio of productive and non-productive $\mathrm{RP}_{0}$ complexes can be modulated by transcription factors and thus offers a layer for gene regulation in the cell (27). On the other hand, recent single-molecule studies revealed long-lived pausing, backtracking and arrest of initially transcribing bacterial and mitochondrial RNAPs that could potentially explain the productive and abortive RNA synthesis by a single type of RPo complexes (28)(29)(30). The RPo formation pathway branching - its occurrence and mechanism - thus warrants further study. 
bioRxiv preprint doi: https://doi.org/10.1101/2021.03.27.437306; this version posted March 28,2021 . The copyright holder for this preprint (which was not certified by peer review) is the author/funder, who has granted bioRxiv a license to display the preprint in perpetuity. It is made available under aCC-BY-NC-ND 4.0 International license.

Here, we utilise single-molecule techniques to complement bulk biochemical assays and resolve asynchronous, multi-step and branched reaction mechanisms during $\sigma^{70}$-dependent $\mathrm{RP}_{0}$ formation. Our results demonstrate that the $\mathrm{RP}_{0}$ formation pathway is indeed branched, resulting in $\mathrm{RP}_{0}$ complexes with markedly different stability in their open transcription bubble conformation. Furthermore, $\alpha$ CTD interactions with the promoter upstream sequence strongly stimulate bubble initiation and tune the reaction pathway towards more stable $\mathrm{RP}_{0}$ complexes. The RNAP cleft loops (and especially the $\beta^{\prime}$ rudder one), play a key role in stabilising the open transcription bubble. We propose that the inherent mechanistic heterogeneity of the $\mathrm{RP}_{0}$ pathway is a prerequisite for transcriptional regulators to strongly modulate the formation and function of RPo complexes, and the rate of transcript generation.

\section{Methods}

Promoter preparation-Labelled and unlabelled DNA oligos to make lacCONS+2 promoter constructs were purchased from IBA Lifesciences (Germany) (Fig. S1A-C). Short lacCONS+2 promoters $(-39 /+25)$ were reconstituted by annealing PAGE purified labelled template and non-template DNA oligos at 1 $\mu \mathrm{M}$ in annealing buffer [ $10 \mathrm{mM}$ Tris- $\mathrm{HCl}(\mathrm{pH} 8.0), 50 \mathrm{mM} \mathrm{NaCl}, 0.1 \mathrm{mM}$ EDTA]. The annealing program consisted of initial denaturation $\left(93^{\circ} \mathrm{C}, 3 \mathrm{~min}\right.$ ) followed by step-wise cooling to $4^{\circ} \mathrm{C}$ (each step: $1.2^{\circ} \mathrm{C}$, $30 \mathrm{~s})$. DNA strands for the long lacCONS +2 promoters $(-89 /+25)$ were constructed using a previously described protocol (29).

Protein preparation-Escherichia coli core RNAPs were expressed in E. coli and purified as previously described (31). The wild-type RNAP was expressed from plasmid pVS10 (T7p- $\left.\alpha-\beta-\beta^{\prime}{ }_{-} \mathrm{His}_{6}-\mathrm{T7} p-\omega\right)$ (32). $\Delta$ Rudder loop RNAP (T7p- $\alpha-\beta-\beta^{\prime}[\Delta$ N309-K325]_TEV_His $10-T 7 p-\omega)$, $\Delta$ lid loop RNAP (T7p- $\alpha-\beta-\beta^{\prime}[\Delta$ P251S263 $\rightarrow$ GG]_TEV_His $10-T 7 p-\omega)$ and $\Delta$ gate loop RNAP (T7p- $\alpha$-His $\left.s_{-} \beta[\Delta R 368-P 376 \rightarrow G G]-\beta^{\prime}-\omega\right)$ were expressed from pM T041, pHM 001 and pTG011, respectively (33). Wild-type E. coli $\sigma^{70}$ was purified as previously described (34). Holoenzymes were assembled by incubating $0.5 \mu \mathrm{M}$ RNAP with $1.5 \mu \mathrm{M} \sigma^{70}$ for $15 \mathrm{~min}$ at $30^{\circ} \mathrm{C}$ in RNAP storage buffer [20 mM Tris- $\mathrm{HCl}(\mathrm{pH} 8.0), 150 \mathrm{mM} \mathrm{NaCl}, 50 \%$ (vol/vol) glycerol, $0.1 \mathrm{mM}$ EDTA, $0.1 \mathrm{mM}$ dithiothreitol (DTT)].

Microscope coverslip preparation-Borosilicate glass coverslips (1.5 MenzelGläzer, Germany) were heated to $500^{\circ} \mathrm{C}$ in oven for $1 \mathrm{~h}$ to reduce background fluorescence. The coverslips were then rinsed with HPLC-grade acetone and immerged into 1\% (v/v) Vectabond (product code \#SP-1800, Vector Labs, CA, USA) in acetone for 10 min to functionalise the glass surface with amino groups. Coverslips were then rinsed with acetone followed by deionized water before drying them under a stream of nitrogen gas. A silicone gasket (103280, Grace Bio-Labs, OR, USA) with four reaction wells was placed in the middle of the coverslip. The coverslip surface was then simultaneously passivated by pegylation against unspecific protein/DNA binding and biotinylated to provide attachment points for specific protein immobilisation. Each well on the coverslip was thus filled with $20 \mu \mathrm{l}$ of $180 \mathrm{mg} / \mathrm{ml}$ methoxyPEG (5 kDa)-SVA (Laysan Bio, AL, USA) and $4.4 \mathrm{mg} / \mathrm{ml}$ biotin-PEG ( $5 \mathrm{kDa})$-SC (Laysan Bio, AL, USA) in $50 \mathrm{mM}$ M OPS-KOH buffer ( $\mathrm{pH} 7.5$ ), incubated for $\sim 3 \mathrm{~h}$ at room temperature and finally the wells were thoroughly rinsed with phosphate-buffered saline (PBS; Sigma Aldrich, UK). The coverslips remained functional for at least two weeks when stored at $4^{\circ} \mathrm{C}$ in plastic pipette tip box containing a layer of deionised water at the bottom. During the storage the coverslip wells were filled with PBS.

Single-molecule experiments-On the day of microscopy experiment, the pegylated coverslips were incubated for $\sim 10 \mathrm{~min}$ with $0.5 \mathrm{mg} / \mathrm{ml}$ of Neutravidin (31050, ThermoFisher Scientific, UK) in $0.5 \times$ PBS and subsequently rinsed with $1 \times$ PBS. The coverslips were then incubated for $\sim 10$ min with $4 \mu \mathrm{g} / \mathrm{ml}$ of Penta $\cdot$ His biotin conjugate antibody (34440, Qiagen, UK) in reaction buffer [ $40 \mathrm{mM}$ HEPES buffer (pH 7.3, BP299100, Fisher Scientific, UK), $100 \mathrm{mM}$ potassium glutamate, $10 \mathrm{mM} \mathrm{M} \mathrm{gCl}, 1 \mathrm{mM}$ DTT, 
bioRxiv preprint doi: https://doi.org/10.1101/2021.03.27.437306; this version posted March 28,2021 . The copyright holder for this preprint (which was not certified by peer review) is the author/funder, who has granted bioRxiv a license to display the preprint in perpetuity. It is made available under aCC-BY-NC-ND 4.0 International license.

$1 \mathrm{mM}$ cysteamine hydrochloride, $5 \%$ glycerol (vol/vol), $0.2 \mathrm{mg} / \mathrm{ml}$ bovine serum albumin] and subsequently rinsed with the reaction buffer.

To analyse the $\mathrm{RP}_{0}$ complex formation in real-time at $22^{\circ} \mathrm{C}$ the anti-His-tag-antibody coated coverslip was incubated $\sim 10$ min with $1 \mathrm{nM}$ label-free holoenzyme in the reaction buffer, rinsed thoroughly with the reaction buffer and mounted on the microscope. $25 \mu \mathrm{l}$ of imaging buffer [i.e., reaction buffer supplemented with $2 \mathrm{mM}$ UV-treated Trolox, $1 \%$ (w/v) glucose, $0.4 \mu \mathrm{g} / \mathrm{ml}$ catalase $(10106810001$, Roche Diagnostics, Germany), $1 \mu \mathrm{g} / \mathrm{ml}$ glucose oxidase (G2133, Sigma Aldrich, UK)] was replaced to the imaged well. Data recorder was started to take an 80 s movie. $1 \mu \mathrm{l}$ of $4 \mathrm{nM}$ promoter in the reaction buffer was gently pipetted to the well at $\sim 8 \mathrm{~s} \mathrm{time-point.} \mathrm{The} \mathrm{formation} \mathrm{of} \mathrm{RNAP-promoter} \mathrm{complexes}$ was evident by the appearance of bright co-localised spots on the Cy3B and ATT0647N fluorescence channels. In some experiments these surface-formed RNAP-promoter complexes were further imaged after exchanging fresh imaging buffer to the well and finding non-bleached field-of-view. The age of RNAP-promoter complexes at the moment of recording these 20 s post-binding movies was 3-7 min. In some control experiments, we monitored the initial RNA synthesis activity RNAP by including $1 \mathrm{mM}$ NTPs (ATP, GTP, CTP and UTP) in the imaging buffer.

To analyse transcription bubble dynamics in pre-assembled $\mathrm{RP}_{0}$ complexes, $2 \mathrm{nM}$ holoenzyme was incubated with $5 \mathrm{nM}$ promoter in reaction buffer for $15 \mathrm{~min}$ at $37^{\circ} \mathrm{C} .100 \mu \mathrm{g} / \mathrm{ml}$ sodium heparin (H4784, Sigma, UK) was added to disrupt non-specific RNAP-promoter complexes and $\sim 1.3 \mu$ of the mixture was transferred to anti-His-tag-antibody coated coverslip well containing $25 \mu$ reaction buffer. The RPo complex immobilisation at $22^{\circ} \mathrm{C}$ was let to continue until $\sim 50$ molecules were detected on the field-of-view. The well was then rinsed with reaction buffer and finally filled with $25 \mu$ imaging buffer. Data was recorded as $20 \mathrm{~s}$ movies from about ten field-of-view per well at $22^{\circ} \mathrm{C}$.

Single RNAP-promoter complexes were imaged using objective-based single-molecule TIRF microscope previously described (35). The donor (Cy3B) and acceptor (ATT0647N) fluorophores in the promoter were excited using $532 \mathrm{~nm}$ and the $642 \mathrm{~nm}$ lasers in alternating laser excitation (ALEX) mode, respectively (36). The emission of donor and acceptor fluorophores was separated from each other and from the excitation light, using dichroic mirrors and optical filters, and recorded side-byside on an electron multiplying charge-coupled device camera (iXon 897, Andor Technologies, Northern Ireland). The frame time of the recordings was 20 ms with 10 ms ALEX excitation by each laser. The measured laser power before the dichroic mirror was set to $\sim 4 \mathrm{~mW}$ and $\sim 1 \mathrm{~mW}$ for the $532 \mathrm{~nm}$ and $642 \mathrm{~nm}$ laser, respectively.

Single-molecule data analysis-The recorded movies were processed with custom-made TwoTone TIRF-FRET analysis software (35) (https://groups.physics.ox.ac.uk/genemachines/group/Main.Software.html) to identify and extract the intensities of co-localised donor and acceptor fluorophores. If the processed movies had fluorescent complexes on the surface already at the beginning of the movie, i.e., post-binding and preformed RPo complex movies (see above), the following Twotone-ALEX parameters were applied to select only complexes containing a single ATT0647N acceptor dye and a single Cy3B donor dye: channel filter as DexDem\&\&AexAem (colocalisation of the donor dye signal upon donor laser excitation, the acceptor dye signal upon acceptor laser excitation), a width limit between the donor and the acceptor between 1 and 2 pixel, a nearest-neighbour limit of 6 pixels, and signal averaging from the frames 2-40. In the case of real-time $\mathrm{RP}_{0}$ complex formation movies, the nearest-neighbour limit was turned off and the time-window for the search of the surface-bound fluorescent molecules was set with the signal averaging setting (i.e. typically frames $\sim 1000-3000$ ) to the part of the movie in which most promoter binding events took place. The trajectories selected by the TwoTone-ALEX analysis were manually sorted by eliminating all traces that displayed extensive fluorophore blinking, 
bioRxiv preprint doi: $\mathrm{https}$ ://doi. org/10.1101/2021.03.27.437306; this version posted March 28, 2021. The copyright holder for this preprint (which was not certified by peer review) is the author/funder, who has granted bioRxiv a license to display the preprint in perpetuity. It is made available under aCC-BY-NC-ND 4.0 International license.

multi-step photobleaching indicating more than one donor or acceptor dye in the same diffraction limited intensity spot, or other aberrant behaviour.

The apparent FRET efficiency ( $\left.E^{*}\right)$ was calculated using Equation 1 where $I_{D D}$ and $I_{D A}$ are the emission intensities of the donor (Су3B) and acceptor (ATT0647N) dyes upon donor excitation (532 nm), respectively (37).

$$
E^{*}=\frac{I_{D A}}{I_{D A}+I_{D D}} \quad \text { Equation } 1
$$

The trajectories were analysed using a modified version of the hidden M arkov model ebFRET software (38) (29) (the modified code is available from the corresponding authors on reasonable request). The trajectories from the pre-formed $\mathrm{RP}_{0}$ or post-binding movies were fit to two-state HMM model followed by noise filtering by requiring an accepted dwell time to satisfy the criteria that the step (i.e., change in $\mathrm{E}^{*}$ ) is separated from the subsequent step by more than 3-fold the Allan deviation (39) (29). The trajectories were then classified into dynamic or static populations depending whether they displayed $>2$ or $\leq 2$ accepted $\mathrm{E}^{*}$ transitions, respectively. The dwell times were extracted from the dynamic trajectories to compile a dwell time distribution. The dwells with undefined length, i.e. the first and last dwell, were discarded at this point.

The trajectories from the real-time $\mathrm{RP}_{0}$ formation movies were analysed separately for the first transcription bubble opening event, i.e., the $\mathrm{RP}_{\mathrm{c}} \rightarrow \mathrm{RP} \mathrm{P}_{\mathrm{o}}$ transition, and transcription bubble dynamics after the RPo formation. The latter analysis was identical to the case of pre-formed RPo complexes with the exception that the $\mathrm{RP}_{\mathrm{C}} \rightarrow \mathrm{RP}_{\mathrm{O}}$ transition at the beginning of the trajectory was trimmed away before HMM . In contrast, the analysis of the $\mathrm{RP}_{\mathrm{C}} \rightarrow \mathrm{RP} \mathrm{P}_{\mathrm{o}}$ transition in the trajectories was performed after trimming away possible bubble dynamics subsequent to the first transcription bubble opening event. We fit the first bubble opening trajectories using two-state $H M M$, i.e., $R_{C} \rightarrow R P_{0}$ mechanism, and three-state $H M M$, i.e., $R P_{c} \rightarrow R P_{i} \rightarrow R P_{0}$ mechanism. The initial fits were filtered by requiring true state transitions to be at least 2-fold the Allan deviation (39) (29). Selection of the more complex 3state model for the trajectory also required that both the HMM lower bound value and Aikake information criteria, calculated as previously described (40), favoured this model. The dwell times in the $\mathrm{RP}_{c}$ and $\mathrm{RP}_{i}$ states were compiled to separate dwell time distributions. The lifetime of the $\mathrm{RP}_{\mathrm{c}}$ state was determined by fitting the dwell time distribution to the mono-exponential decay function using Origin software (OriginLab Corporation, M A, USA). Due to the limited amount of data, the lifetime of $\mathrm{RP}_{i}$ state was calculated as the arithmetic mean and its $95 \%$ confidence interval was estimated by bootstrapping (10000).

The histograms of $E^{*}$ values were fit in Origin software to one or two Gaussian distributions using Equation 2 with $n$ fixed as 1 or 2, respectively. The fit parameters $E_{c}^{*}, w$ and $A$ are the centre, width and area of the Gaussian distributions, respectively.

$$
y=\sum_{0}^{n} \frac{A}{w \sqrt{\pi / 2}} e^{-2 \frac{\left(E^{*}-E_{C}^{*}\right)^{2}}{w^{2}}} \quad \text { Equation } 2
$$


bioRxiv preprint doi: https://doi.org/10.1101/2021.03.27.437306; this version posted March 28,2021 . The copyright holder for this preprint (which was not certified by peer review) is the author/funder, who has granted bioRxiv a license to display the preprint in perpetuity. It is made available under aCC-BY-NC-ND 4.0 International license.

\section{Results}

Direct formation of surface-immobilised catalytically active open complexes

To be able to monitor RNAP-promoter open complex $\left(\mathrm{RP}_{0}\right)$ formation in real-time at the singlemolecule level, we used FRET to look at the changes in distances between two points, i.e., positions 15 and +15 relative to the transcription start site (position +1 ) on a promoter DNA fragment. A fluorophore pair incorporated in positions - 15 (donor) and +15 (acceptor) produces FRET signatures that vary depending on the transcription bubble conformation; this pair has been employed before to monitor conformational changes in populations of single transcription complexes (41)(42), conformational dynamics of RPo complexes (43) and conformational changes after the formation of $\mathrm{RP}_{0}$ complex (29) on a consensus lac promoter (lacCONS+2) (Fig. S1A,B).

Here, we modified our previous protocols to detect the nascent RNAP-promoter complex $\left(\mathrm{RP}_{\mathrm{c}}\right)$ and its subsequent maturation to RPo (Fig. 1). To this end, we attached molecules of the Escherichia coli RNA polymerase- $\sigma^{70}$ holoenzyme to the surface of a coverslip and started imaging the surface using TIRF microscopy (Fig. 1A,B). Subsequent addition of the dual-labelled promoter DNA to the reaction buffer was expected to lead to the appearance of co-localised fluorescent spots on the donor (Cy3B label) and acceptor (ATT0647N label) detection channels of the microscope upon binding to the surface-attached holoenzyme (Fig. 1B). The timing of the appearance of the fluorescent spots on the surface (due to DNA binding and formation of RPc complexes) is precisely defined in the singlemolecule trajectories by the simultaneous appearance of Cy3B and ATT0647N fluorescence signals ("DNA binds" time point, Fig. 1C). The $-15 /+15$ ruler reports low FRET for the RPc complex, and intermediate FRET for the RPo complex, since the formation of the transcription bubble decreases the distance between the -15 and +15 positions in the DNA (43). The $\mathrm{RP}_{\mathrm{C}} \rightarrow \mathrm{RP}_{0}$ transition in the trajectories is thus indicated by a sharp FRET increase ("DNA transcription bubble opens" time point, Fig. 1C), which may occur in one or several steps, depending on the intermediates on the reaction pathway.

Our experimental single-molecule trajectories indeed show the expected fluorescence intensity and FRET signatures of RPc complex formation and isomerisation to the RPo state (Fig. 1D). The moment of RNAP-promoter complex formation was precisely defined by the simultaneous appearance of Cy3B and ATT0647N fluorescence in the single-molecule trajectories (e.g., at $12.25 \mathrm{~s}$ and $13.5 \mathrm{~s}$ in the left and right panels, respectively, of Fig. 1D). The apparent FRET efficiency $\left(E^{*}\right)$ of the first stable complexes was $E^{*} \sim 0.2$ (Fig. 1D), a value identical to that we obtained previously for the closed transcription bubble state (43). After a short time ( $\sim 0.35 \mathrm{~s}$ and $\sim 2 \mathrm{~s}$ in the traces of Fig. 1D), the FRET increased to $E^{*} \sim 0.45$, a value identical to that we obtained previously for the open transcription bubble state (43). DNA binding to the coverslip surface was strictly mediated by the RNAP, since the number of non-specific DNA binding events was negligible in the absence of RNAP on the surface (cf. Fig. S2A to S2B). On the population level, the newly formed RNAP-promoter complexes displayed a bimodal FRET distribution, with mean FRET values $\sim 0.2$ and $\sim 0.45$ (Fig. S2C) contrasting with the unimodal FRET distribution (mean $\sim 0.18$ ) of the protein-free immobilised promoter DNA (Fig. S2D). To test whether the $\sim 0.45$ FRET state is indeed a catalytically competent RPo complex, we added NTPS to the sample buffer; this addition almost eliminated the $\sim 0.45$ FRET state, as expected if $\mathrm{RP}_{0}$ complexes engage RNA synthesis and escape the promoter (Fig. S2C).

To provide further proof for the formation of catalytically active $\mathrm{RP}_{0}$ complexes in situ on the coverslip surface, we performed experiments using a promoter with a different labelling scheme, which is very effective in monitoring the progress of initial transcription (dyes at positions -15 and +20 ; Fig. S1C). The scrunching of the downstream DNA towards the RNAP during initial RNA synthesis leads to a stepwise increase in FRET until RNAP escape from the promoter returns the FRET to a low level (Fig. S3A,B) (24). Example trajectories in Fig. S3C demonstrate abortive initiation and promoter-escape 
bioRxiv preprint doi: https://doi.org/10.1101/2021.03.27.437306; this version posted March 28,2021 . The copyright holder for this preprint (which was not certified by peer review) is the author/funder, who has granted bioRxiv a license to display the preprint in perpetuity. It is made available under aCC-BY-NC-ND 4.0 International license.

events occurring shortly after the formation of the RNAP-promoter complexes. However, we note that some RNAP-promoter complexes (typically $20-50 \%$ of all complexes) on the surface neither form $\mathrm{RP}_{0}$ nor engage RNA synthesis; these molecules remain in stable low FRET state $(\sim 0.2)$ and may thus represent unproductive complexes resulting, e.g., from RNAP binding to the ends of the promoter DNA fragment (Fig. S3D). Because the FRET sensitivity of the $-15 /+15$ or $-15 /+20$ labelled promoters is not sufficient to confidently distinguish RPc complex from non-specific RNAP-DNA complexes, we decided to analyse further only the RNAP-promoter complexes which directly show the appearance of the FRET signature of the RPo complex (i.e., the $\sim 0.45$ FRET state) on the $-15 /+15$ labelled promoter.

Extended promoter upstream sequence stimulates $\mathrm{RP}_{0}$ formation

To study the kinetics of $\mathrm{RP}_{0}$ complex formation in real-time and its modulation by the $\alpha \mathrm{CTD}$-promoter upstream interactions, we performed experiments using a long (DNA extending from position -89 to position +25 ) and short (DNA extending from position -39 to position +25 ) version of the lacCONS+2 promoter (Fig. 2A). We also examined the kinetics of open complex formation by using additional versions of the promoter DNAs, which were either fully double-stranded (dsLC2 promoter; Fig. S1A) or contained a mismatch in the promoter region from -10 to -4 (a.k.a. pre-melted promoter, pmLC2; Fig. S1B).

$\mathrm{RP}_{0}$ formation was inefficient in the case of short dsLC2 at $22^{\circ} \mathrm{C}$; in fact, we could identify only 5 realtime promoter-binding events indicating $\mathrm{RP}_{0}$ complex formation ( $3 \%$ of all promoter-binding events; Fig. 2B); even after prolonged incubation of the RNAP-promoter complexes ( $\sim 5 \mathrm{~min}$ ) on the surface, the RPo complex (i.e., the FRET species with $E^{*}-0.45$ ) was nearly absent from the population histogram (Fig. S4A). In contrast, the $\mathrm{RP}_{0}$ complex formed efficiently at $22^{\circ} \mathrm{C}$ on the long promoters, as well as on the short pre-melted promoter, as seen in the $\mathbf{E}^{*}$ histograms (Fig. S4B,C,D) and individual trajectories (Fig. 2B).

We then performed Hidden M arkov modelling (HM M ) of the trajectories to extract the dwell times in the $\mathrm{RP}_{\mathrm{C}}$ state ( $\mathrm{E}^{*} \sim 0.2$ ) before transcription bubble opening and $\mathrm{RP}_{0}$ complex formation (Fig. 2B). The observed distribution of dwell times in the $\mathrm{RP}_{\mathrm{C}}$ state for the long dsLC2 promoter (Fig. 2C) was fitted to a mono-exponential decay function to determine a mean lifetime for the RPc complex of $1.43 \pm 0.09$ $S( \pm S E)$. We also tried to fit the dwell-time distribution using a double-exponential equation, but rejected this more complex kinetic model because the fit parameters were poorly defined as evident from large SE. Using a similar analysis, we estimated the RPc complex lifetime as $0.35 \pm 0.04 \mathrm{~s}$ on the long pre-melted LC2 (Fig. 2D) and $0.39 \pm 0.03 \mathrm{~s}$ on the short pre-melted LC2 (Fig. 2E), respectively. These values indicate that the $\alpha$ CTD interactions with the upstream sequence ( -89 to -40 ) significantly enhance the isomerisation rate of the $\mathrm{RP}_{\mathrm{c}}$ to $\mathrm{RP}_{0}$ complex; however, this happens only on a fully double-stranded promoter. Because the introduction of the pre-melted region $(-10 /-4)$ to the promoter nearly equalised the rate of $\mathrm{RP}_{\mathrm{c}}$ isomerisation to the $\mathrm{RP}_{0}$ complex on the short and long promoters, the $\alpha$ CTD-promoter interactions appear to predominantly contribute to the lowering of the activation energy of initial transcription bubble nucleation.

A subpopulation of $\mathrm{RP}_{0}$ complexes form via a kinetically significant intermediate

Close inspection of the HMM fit to the RPo formation FRET trajectories revealed that, even though most bubble-opening events were described by a two-state model, (i.e., the promoter conformation in the initial complex changed to the RPo state in a single step; Fig. 2B), a subpopulation included an intermediate state (hereafter, $\mathrm{RP}_{\mathrm{i}}$ complex) between the initial $\mathrm{RP}_{\mathrm{C}}$ and final $\mathrm{RP}_{0}$ states (Fig. 3A).

Specifically, the $\mathrm{RP}_{\mathrm{i}}$ complex was identified in $20 \%$ (exact 95\% binomial confidence interval (44): $11-$ $30 \%$ ), in $14 \%(8-23 \%$ ) and in $14 \%$ (8-23\%) of all trajectories in the case of long dsLC2, long pmLC2 and 
bioRxiv preprint doi: https://doi.org/10.1101/2021.03.27.437306; this version posted March 28,2021 . The copyright holder for this preprint (which was not certified by peer review) is the author/funder, who has granted bioRxiv a license to display the preprint in perpetuity. It is made available under aCC-BY-NC-ND 4.0 International license.

short pmLC2 promoter, respectively. The arithmetic mean lifetime of the identified $\mathrm{RP}_{\text {i }}$ state was 0.32 $\mathrm{s}(95 \% \mathrm{Cl}: 0.18-0.49 \mathrm{~s}, \mathrm{~N}=15), 0.15 \mathrm{~s}(0.07-0.26 \mathrm{~s}, \mathrm{~N}=13)$ and $0.17 \mathrm{~s}(0.10-0.23 \mathrm{~s}, \mathrm{~N}=13)$ on the long dsLC2, long pre-melted LC2 and short pre-melted LC2 promoter, respectively. Estimated lifetimes overlap within the confidence interval, suggesting that the lifetime does not depend strongly on the used promoter type. Further, the lifetime estimates indicate that the absence of the RP, state in most trajectories is not explained by our existing temporal resolution (20 ms per frame); even in the worstcase scenario (assuming the shortest lifetime, $0.07 \mathrm{~s}$, within the $\mathrm{Cl}$ and assumed single exponential dwell distribution), the $\mathrm{RP}_{i}$ state would be missed only in $25 \%$ of the trajectories. The expected missing rate drops to only $6 \%$ when the mean $\mathrm{RP}_{\mathrm{i}}$ lifetime on the long dsLC2 promoter $(0.32 \mathrm{~s})$ is used in the calculations.

To compare the mean FRET of the $\mathrm{RP}_{i}$ intermediate to that of the $\mathrm{RP}_{\mathrm{c}}$ and $\mathrm{RP} \mathrm{P}_{0}$ complexes, we extracted FRET efficiency histograms from HM M -segmented trajectories for each of the three states (Fig. 3B). The mean FRET values, obtained as the centres of the fit Gaussian distribution (Equation 2), were found as $0.196 \pm 0.001$ ( $\pm \mathrm{SE}$ ), $0.318 \pm 0.002$ and $0.448 \pm 0.001$ for the $\mathrm{RP}_{\mathrm{c}}, \mathrm{RP}_{\mathrm{i}}$ and $\mathrm{RP}_{0}$ complex, respectively. The mean FRET values suggest that the average distance between the -15 and +15 labels in the $\mathrm{RP}_{i}$ state has become shorter than in the $\mathrm{RP}_{\mathrm{c}}$ complex but remains still longer than in the mature RPo complex.

To probe the structural origin of the $\mathrm{RP}_{\mathrm{i}}$ state, we included in the reaction buffer the RNAP inhibitor myxopyronin B (M yx). Biochemical and structural studies using $M$ yx (45) and structural studies using corallopyronin A (Cor) (9), a Myx analogue, have suggested that this class of RNAP inhibitors block the formation of RPo complex by preventing the loading of template DNA strand into the active site cleft. We observed that the FRET distribution of the RNAP-promoter complexes preformed in the presence of M yx was described by two Gaussians with mean FRET values $0.231 \pm 0.001$ and $0.307 \pm 0.010$ (Fig. 3C, long dsLC2 promoter). The inspection of individual trajectories revealed three classes of molecules: the first and most abundant class involved RNAP-promoter-M yx complexes characterised by an $\mathrm{E}^{*}$ $\sim 0.3$ state $(N=58,60 \%$ of all molecules, Fig. S5A). Interestingly, a sub-fraction $(N=19 / 58)$ of these molecules stochastically sampled a very short-lived, i.e., typically 20-40 ms (1-2 frames), higher E* state (Fig. S5B). The second class of molecules involved potential non-productive complexes as indicated by a stable $\mathrm{E}^{*} \sim 0.2$ value ( $\mathrm{N}=37,38 \%$, Fig. $\mathbf{S 5 C}$ ) and the third class involved $\mathrm{RP}_{0}$ complexes characterized by a long-lived $E^{*} \sim 0.45$ state ( $N=2,2 \%$, Fig. S5D). Preformed complexes on the long pre-melted LC2 promoter confirmed the bimodal FRET distribution with two sub-populations having mean $E^{*}$ values of $0.224 \pm 0.002$ and $0.290 \pm 0.045$ (Fig. S5E).

Consistent with the above equilibrium FRET values, $32 \%(\mathrm{~N}=21)$ of real-time promoter binding trajectories in the presence of $\mathrm{Myx}$ inhibitor demonstrated the formation of initial $\mathrm{RP}_{\mathrm{c}}$ complex $\left(E^{*} \sim 0.2\right)$ and its subsequent isomerisation to $E^{*} \sim 0.3$ state (Fig. S5F) while the remaining $68 \%(N=45)$ of the nascent RNAP-promoter complexes maintained the $E^{*} \sim 0.2$ state for the entire duration of the trajectory (Fig. S5G). The increasing trend in observed FRET values as the RNAP-promoter complexes react towards $\mathrm{RP}_{0}$ is consistent with structural modelling data; the distance between the -15 and +15 labels decreases from $98 \AA$ in the RPc complex, to $87 \AA$ in the Cor-stabilised RNAP-promoter intermediate, and further to $66 \AA$ in the RPo complex (Fig. S5H). We thus suggest that the RP intermediate, which we detected in a subpopulation of the RPo formation FRET trajectories, resembles the Myx/Cor-stabilised RNAP-promoter complex previously characterised by cryo-EM (9) with respect to the downstream DNA residing in the RNAP cleft and the exclusion of the template DNA from the active site (Fig. S5H). Consistent with these complexes resembling a real on-pathway intermediate, Boyaci et al. (9) identified by cryo-EM a very similar RNAP-promoter structure (named as RP i2 in ref. (9)) also in the absence of Cor inhibitor (Fig. S5H). 
bioRxiv preprint doi: https://doi.org/10.1101/2021.03.27.437306; this version posted March 28,2021 . The copyright holder for this preprint (which was not certified by peer review) is the author/funder, who has granted bioRxiv a license to display the preprint in perpetuity. It is made available under aCC-BY-NC-ND 4.0 International license.

Transcription bubble opening leads to static and dynamic RPo complexes

We next analysed the transcription bubble behaviour immediately after initial RPo complex formation; our observation span for these measurements was 1.3-22 $\mathrm{s}$ (median $=4 \mathrm{~s}, \mathrm{~N}=119$ ). HM M analysis of the trajectories revealed two RPo complex sub-populations: a "static" (or "stable") sub-population (73\% of the nascent $\mathrm{RP}_{0}$ complexes; exact $95 \%$ binomial $\mathrm{Cl}: 64-81 \%$ ), where the transcription bubble remained open for the entire duration of the trajectory (reflected by an $E^{*} \sim 0.45$ state; Fig. 4A); and a dynamic sub-population (27\%, Cl: $19-36 \%$ ), where the transcription bubble fluctuates rapidly between the open state $\left(E^{*}-0.45\right)$ and state(s) characterised by lower FRET (Fig. 4B). The dynamic RPo complexes do not appear to convert to a static $\mathrm{RP}_{0}$ within our observation span, suggesting that the dynamic $\mathrm{RP}_{0}$ - like complex is not an on-pathway intermediate which eventually isomerises to form the stable RPo complex. This conclusion, which invokes the formation of static and dynamic RPo complexes on parallel pathways, is also supported by the presence of a similar distribution of static and dynamic $\mathrm{RP}_{0}$ complexes in samples of preformed, heparin-challenged RNAP-promoter complexes (see next section of the manuscript and ref. (43)). Notably, both the 2-state (i.e., showing no RP intermediate; Fig. 2B) and 3-state (Fig. 3A) bubble-opening mechanisms produced both static and dynamic $\mathrm{RP}_{0}$ complexes (Fig. $\mathbf{4 C}$ ), suggesting that the presence of the $\mathrm{RP}_{\mathrm{i}}$ intermediate does not dictate the subsequent stability of the bubble.

To evaluate the bubble conformations accessed by the dynamic RPo complexes, we analysed the $\mathrm{E}^{*}$ distribution of these complexes, which was fit well by two Gaussian functions with mean $E^{*}$ values of $0.265 \pm 0.004$ and $0.467 \pm 0.001$ (Fig. 4D). In contrast, the $E^{*}$ histogram of the static RPo showed only a single distribution centred at $E^{*}$ of $0.448 \pm 0.001$ (Fig. 3B). These values suggest that the dynamic $\mathrm{RP}_{0}$ complexes do not sample either the $\operatorname{RP}_{\mathrm{c}}\left(\mathrm{E}^{*} \sim 0.20\right)$ or the on-pathway intermediate $\mathrm{RP}_{\mathrm{i}}\left(\mathrm{E}^{*} \sim 0.32\right)$ states. Instead, it is more likely that the dynamic RPo complexes sample an off-pathway state, which is characterised by $\mathrm{E}^{*} \sim 0.27$ and which we coin as $\mathrm{RP}_{\mathrm{ISO}}$.

The role of RNAP-promoter upstream interactions in the $\mathrm{RP}_{0}$ pathway selection

We next evaluated how RNAP $\alpha$ CTD-promoter upstream sequence interactions contribute to the relative formation of stable and dynamic $\mathrm{RP}_{0}$ complexes and the kinetic parameters of the transcription bubble dynamics. To this end, we prepared $\mathrm{RP}_{0}$ complexes at $37^{\circ} \mathrm{C}$ using either a short or a long dsLC2, challenged them with heparin, i.e., a DNA competitor, and immobilised them on the coverslip surface for smFRET analysis. In this protocol, $\mathrm{RP}_{0}$ complexes also form on the short dsLC2 promoter fragments, allowing direct comparison to the long dsLC2 promoter (Fig. S6A). HM M -based classification of the trajectories indicated that the dynamic $\mathrm{RP}_{0}$ complexes were 1.7 -fold more prevalent ( $25 \pm 3.6 \%$ vs $15 \pm 2.7 \%$ of all complexes; mean and SD of three independent experiments) on the short promoter compared to the long promoter (Fig. S6B). A two-sample T-test $(p=0.035)$ confirmed that the observed difference in the relative number of dynamic complexes on the two promoters is statistically significant. Further, the observation span for the measurements was 2.0-25 $\mathrm{s}$ (median $8.0 \mathrm{~s}, \mathrm{~N}=348$ ) on the long promoter and 1.4-25 $\mathrm{s}$ (median $6.9 \mathrm{~s}, \mathrm{~N}=435$ ) on the short promoter, indicating that the higher prevalence of dynamic $\mathrm{RP}$ o complexes on the short promoter is not explained simply by longer trajectories that accumulate more state transitions. The mean dwell-

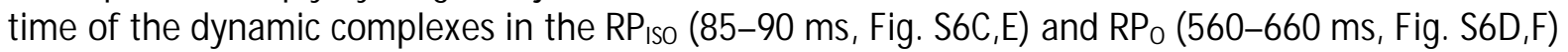
states were similar on both promoters (Fig. S6G). Our results suggest that the $\alpha$ CTD-promoter interactions steer the RPo pathway selection towards the static RPo complex; however, the effect is moderate, and significant number of dynamic $\mathrm{RP}_{0}$ complexes form also on the long promoter. The similarity in the timescales of transcription bubble dynamics on the short and long promoters also indicates that the bubble isomerisation rates are independent of the status of the $\alpha$ CTD-promoter upstream sequence interactions. 
bioRxiv preprint doi: https://doi.org/10.1101/2021.03.27.437306; this version posted March 28,2021 . The copyright holder for this preprint (which was not certified by peer review) is the author/funder, who has granted bioRxiv a license to display the preprint in perpetuity. It is made available under aCC-BY-NC-ND 4.0 International license.

The role of RNAP cleft loops in the $\mathrm{RP}_{0}$ stabilisation

To interrogate protein structural elements contributing to the RPo stability, we deleted the $\beta$ gate loop $(\Delta \mathrm{GL}), \beta^{\prime}$ rudder loop $(\Delta \mathrm{RL})$ or $\beta^{\prime}$ lid loop $(\Delta \mathrm{LL})$ from the RNAP and determined the effects of these deletions on the transcription bubble dynamics using preformed $\mathrm{RP}_{0}$ complexes. Structurally, $\mathrm{GL}$ mediates the RNAP $\beta$-pincer interaction with the RNAP $\beta^{\prime}$-clamp, thus forming a barrier for the DNA entry and exit from the RNAP cleft (Fig. 5A) (9)(10); RL locates between the tDNA and ntDNA strands in the $\mathrm{RP}_{0}$; and $\mathrm{LL}$ locates adjacent to the RL and is able to interact with the tDNA around base - 6 in the $\mathrm{RP}_{\mathrm{O}}$.

We used 2-state HMM of FRET trajectories to classify RPo complexes into static (i.e., no bubble dynamics) and dynamic (Fig. 5B) and found that all deletions shifted the balance of $\mathrm{RP}_{\mathrm{O}}$ formation towards the direction of dynamic RPo complexes. The effects of $\Delta \mathrm{GL}$ and $\Delta \mathrm{LL}$ were moderate, as they increased the fraction of dynamic RPo complexes from the wild-type (WT) RNAP level by 1.3-1.4-fold, i.e., from $26 \%$ (exact $95 \%$ binomial Cl: $22-31 \%$ ) in WT to $34 \%$ (Cl: $29-40 \%$ ) in $\Delta \mathrm{LL}$ and $36 \%$ (Cl: $30-$ 43\%) in $\Delta \mathrm{GL}$ (Fig. 5C). However, the $\Delta \mathrm{RL}$ effect was much stronger, 2.9-fold, making most RPo complexes, i.e., $77 \%$ (Cl: $72-83 \%$ ), dynamic. Kinetic analysis of the dynamic RPo's indicated that $\Delta \mathrm{RL}$ and $\Delta \mathrm{LL}$ shortened the lifetime of the open bubble state by 2.8 -fold, whereas $\Delta \mathrm{GL}$ had no effect (Fig. $\mathbf{5 D}, \mathbf{E})$. In contrast, all three mutations increased the lifetime of the $\mathrm{RP}$ iso state. Specifically, the $\mathrm{RP}_{\text {iso }}$ lifetime increased by 2.5-, 1.8- and 1.5-fold in the case of $\Delta \mathrm{LL}, \Delta \mathrm{RL}$ and $\Delta \mathrm{GL}$ mutant RNAPs, respectively (Fig. 5F,G). Notably, the median observation span for these measurements was $4.26 \mathrm{~s}, 4.84 \mathrm{~s}, 5.20 \mathrm{~s}$ and $6.00 \mathrm{~s}$ in the case of WT, LL, GL and RL, respectively. The variation in the observation span, however, does not significantly contribute to the classification of the molecules to the static and dynamic RPo classes or kinetic parameters because, even in the combination of shortest trajectories (median $4.26 \mathrm{~s}$ ) and most stable state, i.e., wild-type RPo complex (lifetime $0.5 \mathrm{~s}$ ), the probability that $\mathrm{RP}_{0} \rightarrow \mathrm{RP}_{\mathrm{Iso}}$ transition does not take place within the trajectory is extremely small (only 0.0002 ). Collectively, our data indicate that the $\mathrm{GL}, \mathrm{RL}$ and $\mathrm{LL}$ domains in the RNAP contribute to the RPo pathway branching (by changing the balance between static and dynamic RPo complexes) and affect the rates of the transcription bubble conformation changes.

\section{Discussion}

In this work, we establish the ability to look at the earliest stages of transcription initiation in real-time and at the single-molecule level. This unique capability bypasses the need to synchronise complexes and offers unprecedented access to co-existing reaction pathways and transient intermediates; as a result, we gained new mechanistic insight about the paths and intermediates used by RNA polymerase to form $\sigma^{70}$-dependent RPo complexes on a lac promoter derivative. Our work also provides further insight on the dynamics and heterogeneity of open complexes and their determinants, as well as their potential biological role in gene regulation.

Open complex formation may proceed via more than one path. Our data indicate that the $\mathrm{RP}_{\mathrm{C}} \rightarrow \mathrm{RP}_{\mathrm{O}}$ isomerisation step involves mechanistic branching. In most cases (80-86\% of molecules), the isomerisation occurred in one apparent step without observable intermediate(s) within our 20-ms temporal resolution, suggesting that bubble initiation was followed by rapid bubble progression, downstream DNA loading to the RNAP cleft, and template DNA loading to the active site cleft. However, the remaining molecular trajectories (14-20\%) displayed an intermediate state (RP. between the $\mathrm{RP}_{\mathrm{c}}$ and $\mathrm{RP}_{\mathrm{o}}$. Given the $\mathrm{RP}_{\mathrm{i}}$ lifetime and our temporal resolution, we excluded the possibility that all the trajectories without an identified $\mathrm{RP}_{i}$ are due to its short lifetime; instead, our data support the presence of parallel paths for $\mathrm{RP}_{0}$ formation, or at least, the presence of RNAP populations with different propensity to form an open complex. 
bioRxiv preprint doi: https://doi.org/10.1101/2021.03.27.437306; this version posted March 28,2021 . The copyright holder for this preprint (which was not certified by peer review) is the author/funder, who has granted bioRxiv a license to display the preprint in perpetuity. It is made available under aCC-BY-NC-ND 4.0 International license.

Possible structure of $\mathbf{R} \mathbf{P}_{\mathbf{i}}$. Based on the observed FRET efficiencies, the intermediate may have structural similarities to an RNAP-promoter complex stabilised by an antibiotic targeting RNAP. Recent cryo-EM data of Mycobacterium tuberculosis RNAP showed that corallopyronin A (a Myx analogue) stabilises a partially melted transcription bubble (region -11/-4) (9), consistent with earlier biochemical footprinting data (45). The same cryo-EM work showed that a similar conformation was present in the absence of $\mathrm{Myx}$, raising the possibility that the observed conformation may represent an intermediate on the RPo pathway (9). Our real-time trajectories using E. coli RNAP clearly show the presence of an intermediate $\left(\mathrm{RP}_{\mathrm{i}}\right)$ that has a structural signature similar to that expected by a partially melted bubble. Another possibility for the structure of the $\mathrm{RP}_{\mathrm{i}}$ is an intermediate where all the melting has been completed, but the template DNA has not been loaded to the active site cleft; such a structure is supported by results showing that the presence of $M y x$ does not prevent full opening of DNA, as sensed by fluorescence enhancement of a Cy3 probe introduced at position +2 (46); such enhancement is expected when the bubble opening has been complete. However, at least on lac promoter, the intermediate is kinetically significant only in a small fraction of $\mathrm{RP}_{\mathrm{o}}$ formation events.

Possible sources for heterogeneity in open complex formation pathways. Since the $\mathbf{R P}_{\mathbf{i}}$ is detectable only in a subset of trajectories, it is conceivable that, for those trajectories, a structural module of the RNAP delays downstream bubble melting and/or tDNA loading to the active site cleft. One candidate for such a structural module is the RNAP $\boldsymbol{\beta}^{\prime}$ switch-2 segment. Based on mutational analysis, structural studies, and observed $M$ yx effects, it has been established that the switch-2 region can adopt two different conformations (45). The conformation dominant in the absence of $\mathrm{M} y \mathrm{x}$ is compatible with template loading to the active site; in contrast, the alternative conformation (which is stabilised by $M y x$ and specific mutations in the switch-2) blocks template loading to the active site. If the switch-2 was at the moment of DNA bubble initiation in the blocking conformation in a small fraction of RNAPs, the loading of template DNA to the active site cleft would be delayed by the necessary switch-2 refolding. This hypothesis also predicts that the kinetics of the switch-2 conformational change (from the blocking conformation to the permissive conformation) controls the rate of formation of $\mathrm{RP}_{0}$ in a population of RNAPs.

The $\mathrm{RP}_{\mathrm{i}}$ heterogeneity may also result from alternative promoter discriminator (region $-6 /+1$ ) conformations in different RNAP molecules. This hypothesis is supported by the previous finding that $\mathrm{G}^{-6} \mathrm{G}^{-5} \mathrm{G}^{-4}$ and $\mathrm{C}^{-6} \mathrm{C}^{-5} \mathrm{C} / \mathrm{T}^{-4}$ motifs in the ntDNA stabilised in crystallo two distinct discriminator conformations and imposed in solution one base-pair difference in the predominant transcription start site (47). GTG motif, which is found in our promoter, had transcription start site statistics halfway between the GGG and CCC/T motifs, consistent with the assumption that a promoter with this motif can readily adopt either of the two discriminator conformations.

$\mathbf{R P}_{0}$ complexes appear to have different stability immediately after their formation. A longstanding question in the transcription field is whether all $\mathrm{RPo}$ on a given promoter are the same or differ in their structural and functional properties (22)(23)(24)(25). Our results show that indeed there is another layer of heterogeneity as indicated by the differing stability of the transcription bubble, even immediately after $\mathrm{RP}_{0}$ formation (as judged by the appearance of the $\mathrm{E}^{*} \sim 0.45$ state). Most $\mathrm{RP}_{0}$ complexes can keep the bubble open for at least several seconds; however, a more dynamic RPo subpopulation samples different bubble states in the millisecond timescale. The stable or dynamic RPo mode was set before or during the first-time opening of the bubble and the modes did not interconvert within our observation span ( -8 seconds); this observation rules out the possibility that the dynamic RPo were indeed intermediates on the linear pathway leading to the stable $\mathrm{RP}_{0}$ complexes. This new insight aligns well with our previous observation of stable and dynamic RPo molecules within the population of pre-formed RPo complexes (43), while allowing further mechanistic insight by linking the formation of stable and dynamic complexes on the existence of a 
bioRxiv preprint doi: https://doi.org/10.1101/2021.03.27.437306; this version posted March 28,2021 . The copyright holder for this preprint (which was not certified by peer review) is the author/funder, who has granted bioRxiv a license to display the preprint in perpetuity. It is made available under aCC-BY-NC-ND 4.0 International license.

branched $\mathrm{RP}_{\mathrm{O}}$ pathway and the sampling of a short-lived off-pathway state (RP $\left.{ }_{\text {Iso }}\right)$ by the dynamic RPo's.

The analysis of mutant RNAPs suggest that the main difference between the dynamic and stable $\mathrm{RP}_{0}$ complexes arises from the RNAP interaction with the single-stranded template DNA in the active site cleft. The deletion of rudder loop, which presses against the template DNA positions -7 to -9 , tripled the amount of dynamic RPo (from $26 \%$ to $77 \%$; Fig. 5C) and decreased 3-fold the open bubble lifetime in the dynamic $\mathrm{RP}_{0}$ complexes (Fig. $\mathbf{5 E}$ ). The deletion of lid loop, which interacts with the template DNA base -6 , had a similar effect on the open bubble lifetime. We previously found that deletion of the $\sigma^{70} 3.2$ region (the $\sigma$ "finger", which interacts with the template DNA strand from bases -3 to -6 ), destabilised the $\mathrm{RP}_{0}$ (43). These interactions with the template DNA form late in the RPo mechanism, i.e., when the bubble forms fully and the template DNA strand loads to the active site cleft. Our data suggest that these final interactions form by two alternative ways generating "tight" and "loose" template DNA binding modes: the tight binding mode gives rise to the stable $\mathrm{RP}_{0}$ complexes, and the loose binding mode gives rise to the dynamic RPo complexes.

The presence of such dramatic differences in $\mathrm{RP}_{0}$ stability may have functional consequences, and may be related to reports of non-uniform $\mathrm{RP}_{0}$ function. Specifically, a subset of $\mathrm{RP}_{0}$ complexes (on many promoters) appear to be locked in an abortive initiation mode, in which they repetitively synthesise short RNA products $(<12$-mer, with the exact sequence depending on the specific promoter), whereas another $\mathrm{RP}_{0}$ subset escape the promoter efficiently and synthesise full-length RNA products $(22)(23)(24)(25)$. The failure of promoter escape may also result from long-lived backtracking and arrest of initially transcribing RNAPs (28)(29). The RPo's apparently locked in the abortive mode are also referred as "moribund" complexes, and they apparently have a role in transcription regulation in the cell (27). M echanistically, the dynamic RPo could be candidates to form such moribund complexes, since unstable template DNA binding to the active site is likely to enhance the dissociation probability of short RNAs, leading to abortive initiation. Consistent with this reasoning, the $\Delta 3.2 \sigma^{70}$ mutant (which increase RPo dynamics substantially) released 4-7-mer RNAs more efficiently compared to the WT (24).

Role of the promoter upstream interactions on the $\mathbf{R P}_{0}$ formation and stability. The RNAP $\alpha$ CTDs interact with the promoter upstream sequences either by specifically recognising the promoter UP element (18) or via sequence-independent interactions (14)(19); both interactions are important for $\mathrm{RP}_{\mathrm{o}}$ formation. We found that the upstream part of the lacCONS+2 promoter (from -40 to -89; Fig. S2A-B), which does not contain a full UP element but is similar to the distal UP subsite (48), facilitates transcription bubble melting in the context of fully double-stranded promoters. In fact, the short double-stranded promoter (which lacks $\alpha$ CTDs interactions) failed to form RPo under our experimental conditions, which involve measurements at room temperature. On the other hand, if the requirement for the DNA melting nucleation was bypassed (e.g., by using a pre-melted promoter), the $\alpha C T D$ interactions with upstream sequence no longer increased the rate of $\mathrm{RP}_{0}$ formation (Fig. 2D,E). This finding is consistent with previous biochemical studies showing that the $\alpha$ CTD interactions with the UP element enhance both the initial promoter binding and subsequent isomerisation to competitorresistant conformation (14)(19).

We also found that the presence of upstream sequence interactions did not substantially change the ratio of initial bubble opening events that occur in one step or in two steps (i.e., via the $\mathrm{RP}_{\mathrm{i}}$ ), and did not significantly change the rates of transcription bubble dynamics in the pre-formed RPo. However, the dynamic $\mathrm{RP}_{0}$ complexes formed more often on the short promoter in comparison to the long promoter ( $25 \%$ vs. $16 \%$ ), suggesting that the $\alpha$ CTD-promoter interactions, instead of being fully decoupled from mechanistic steps occurring after the bubble nucleation, have a role in the late steps of RPo pathway branching; the exact mechanism of such modulation is unclear, but it may involve 
bioRxiv preprint doi: https://doi.org/10.1101/2021.03.27.437306; this version posted March 28, 2021. The copyright holder for this preprint (which was not certified by peer review) is the author/funder, who has granted bioRxiv a license to display the preprint in perpetuity. It is made available under aCC-BY-NC-ND 4.0 International license.

bending of the upstream sequence on the RNAP surface (17) and subsequent interactions that affect RNAP conformation dynamics in a way that it influences bubble dynamics.

A working model for the $\mathbf{R P}_{\mathbf{0}}$ formation mechanism. We summarise our key findings in the context of the RPo formation mechanism in Fig. 6 (2). The process begins with the RPc complex formation as the RNAP holoenzyme binds to the promoter and establishes interactions with the - 35 element, -10 element and upstream sequences. Interaction of aCTDs with upstream sequences stimulate RPo formation by bending the upstream DNA around the RNAP (12)(13)(14)(15)(16)(17) and coupling it energetically with bubble formation.

The initial nucleated bubble expands via two different mechanistic paths: in the first path (most common for our lac promoter derivative), the RNAP melts the entire bubble and loads the template DNA strand to the active site cleft in one apparent step without detectable intermediates; the second path, however, involves a short-lived intermediate, $\mathrm{RP}_{\mathrm{i}}$, which features partial bubble melting or incomplete template loading to the active site cleft. We hypothesise that the intermediate appears when a mobile element of the RNAP, e.g., the switch-2 module, is initially in a conformation incompatible with template loading to the active site cleft or if an alternative promoter discriminator conformation delays the full bubble melting in a subset of RNAP-promoter complexes. Template DNA loading to the active site cleft leads to the tight-binding and loose-binding states, which do not readily interconvert. Because stable and dynamics RPo complexes formed with similar probability both directly from $R P_{c}$ and via $R_{i}$, we assume that these pathways merge before the branching to the stable and dynamics RPo's takes place at the template DNA loading step (Fig. 6). The tight template DNA binding mode keeps transcription bubble open whereas the loose-binding features dynamic movement of the template DNA. Template DNA interactions with the RNAP rudder loop and $\sigma$ finger are part of the key determinants of tight binding mode.

Within this mechanistic framework, transcription initiation can be modulated by transcription factors or small-molecule regulators that change RNAP interactions with upstream sequences since such interactions strongly affect promoter binding (14)(19) and DNA melting kinetics. The pathway branching to static and dynamic $\mathrm{RP}_{0}$ may be the underlying cause of complexes being locked in abortive initiation $(22)(23)(24)(25)$. The inherent mechanistic heterogeneity of the RPo formation pathway may amplify the effects of transcription regulators and promoter sequence by converting relatively modest perturbations into large changes in the formation rate, stability and functional properties of the RPo complexes. For example, GreB transcription factor was previously found to block the RPo pathway to a step after the RPc formation (49) whereas copper efflux regulator CueR modulated the formation probability of active and inactive RNAP-promoter complexes (50).

\section{Data availability}

All our time-trace data and the HMM software we used for their analysis will be available to any interested party upon request.

\section{Funding}

This work was supported by Academy of Finland [grant numbers 307775, 314100, 335377 to A.M .M ]; Instrumentarium Science Foundation [grant to A.M .M.]; Finnish Cultural Foundation [grants to A.M .M. and O.P.]; Wellcome Trust grant [grant number 110164/Z/15/Z to A.N.K.]; and UK Biotechnology and Biological Sciences Research Council [grant number BB/H01795X/1 to A.N.K]. 
bioRxiv preprint doi: https://doi.org/10.1101/2021.03.27.437306; this version posted March 28, 2021. The copyright holder for this preprint (which was not certified by peer review) is the author/funder, who has granted bioRxiv a license to display the preprint in perpetuity. It is made available under aCC-BY-NC-ND 4.0 International license.

\section{Acknowledgements}

We thank Richard E. Ebright for providing myxopyronin B. We are grateful to Matti Turtola, Thadée Grocholski and Henri Malmi for constructing plasmids. We thank Abhishek Mazumder for insightful discussions and critical reading of the manuscript. We thank the Cell Imaging and Cytometry core at Turku Bioscience Centre, which is supported by Biocenter Finland, for the access to the microscopes.

\section{References}

1. Feklístov,A., Sharon,B.D., Darst,S.A. and Gross,C.A. (2014) Bacterial Sigma Factors: A Historical, Structural, and Genomic Perspective. Annu. Rev. Microbiol., 68, 357-376.

2. Ruff,E.F., Record,M.T. and Artsimovitch,I. (2015) Initial events in bacterial transcription initiation. Biomolecules, 5, 1035-1062.

3. Campbell,E.A., Korzheva,N., M ustaev,A., Murakami,K., Nair,S., Goldfarb,A. and Darst,S.A. (2001) Structural mechanism for rifampicin inhibition of bacterial RNA polymerase. Cell, 104, 901-912.

4. Feklistov,A., M ekler,V., Jiang,Q., Westblade,L.F., Irschik,H., Jansen,R., M ustaev,A., Darst,S.A. and Ebright,R.H. (2008) Rifamycins do not function by allosteric modulation of binding of $\mathrm{M} \mathrm{g}^{2+}$ to the RNA polymerase active center. Proc. Natl. Acad. Sci. U. S. A., 105, 14820-14825.

5. Lin,W., Das, K., Degen,D., M azumder,A., Duchi,D., Wang,D., Ebright,Y.W., Ebright,R.Y., Sineva,E., Gigliotti,M., Srivastava, A., Mandal,S., Jiang,Y., Liu,Y., Yin,R., Zhang,Z., Eng,E.T., Thomas,D., Donadio,S., Zhang,H., Zhang,C., Kapanidis,A.N. and Ebright,R.H. (2018) Structural Basis of Transcription Inhibition by Fidaxomicin (Lipiarmycin A3). M ol. Cell, 70, 60-71.e15.

6. Ho,M.X., Hudson,B.P., Das,K., Arnold,E. and Ebright,R.H. (2009) Structures of RNA polymeraseantibiotic complexes. Curr. Opin. Struct. Biol., 19, 715-723.

7. Zuo,Y. and Steitz,T.A. (2015) Crystal Structures of the E. coli Transcription Initiation Complexes with a Complete Bubble. Mol. Cell, 58, 534-540.

8. Bae,B., Feklistov,A., Lass-Napiorkowska,A., Landick,R. and Darst,S.A. (2015) Structure of a bacterial RNA polymerase holoenzyme open promoter complex. Elife, 4:e08504.

9. Boyaci,H., Chen,J., Jansen,R., Darst,S.A. and Campbell,E.A. (2019) Structures of an RNA polymerase promoter melting intermediate elucidate DNA unwinding. Nature, 565, 382-385.

10. Chen,J., Chiu,C., Gopalkrishnan,S., Chen,A.Y., Olinares,P.D.B., Saecker,R.M ., Winkelman,J.T., Maloney,M .F., Chait,B.T., Ross,W., Gourse,R.L., Campbell,E.A. and Darst,S.A. (2020) Stepwise Promoter Melting by Bacterial RNA Polymerase. Mol. Cell, 78, 275-288.e6.

11. Mazumder,A. and Kapanidis,A.N. (2019) Recent Advances in Understanding $\sigma^{70}$-Dependent Transcription Initiation Mechanisms. J. Mol. Biol., 431, 3947-3959.

12. Craig,M.L., Tsodikov,O. V., M cQuade,K.L., Schlax,P.E., Capp,M.W., Saecker,R.M . and Record,M .T. (1998) DNA footprints of the two kinetically significant intermediates in formation of an RNA polymerase-promoter open complex: Evidence that interactions with start site and downstream DNA induce sequential conformational changes in polymerase and DNA. J. Mol. Biol., 283, 741756.

13. Sclavi,B., Zaychikov,E., Rogozina,A., Walther,F., Buckle,M. and Heumann,H. (2005) Real-time characterization of intermediates in the pathway to open complex formation by Escherichia coli RNA polymerase at the T7A1 promoter. Proc. Natl. Acad. Sci. U. S. A., 102, 4706-4711.

14. Davis,C.A., Capp,M.W., Record,M .T. and Saecker,R.M. (2005) The effects of upstream DNA on open complex formation by Escherichia coli RNA polymerase. Proc. Natl. Acad. Sci. U. S. A., 102, 285290.

15. Rogozina,A., Zaychikov,E., Buckle,M., Heumann,H. and Sclavi,B. (2009) DNA melting by RNA polymerase at the T7A1 promoter precedes the rate-limiting step at $37^{\circ} \mathrm{C}$ and results in the 
bioRxiv preprint doi: https://doi org/10.1101/2021.03.27.437306; this version posted March 28,2021 . The copyright holder for this preprint (which was not certified by peer review) is the author/funder, who has granted bioRxiv a license to display the preprint in perpetuity. It is made available under aCC-BY-NC-ND 4.0 International license.

accumulation of an off-pathway intermediate. Nucleic Acids Res., 37, 5930-5404.

16. Mangiarotti,L., Cellai,S., Ross,W., Bustamante,C. and Rivetti,C. (2009) Sequence-Dependent Upstream DNA-RNA Polymerase Interactions in the Open Complex with $\lambda$ PR and $\lambda$ PRM Promoters and Implications for the M echanism of Promoter Interference. J. Mol. Biol., 385, 748-760.

17. Sreenivasan,R., Heitkamp,S., Chhabra,M., Saecker,R., Lingeman,E., Poulos,M., M cCaslin,D., Capp,M.W., Artsimovitch,I. and Record,M .T. (2016) Fluorescence Resonance Energy Transfer Characterization of DNA Wrapping in Closed and Open Escherichia coli RNA Polymerase- $\lambda$ PR Promoter Complexes. Biochemistry, 55, 2174-2186.

18. Estrem,S.T., Gaal,T., Ross,W. and Gourse,R.L. (1998) Identification of an UP element consensus sequence for bacterial promoters. Proc. Natl. Acad. Sci. U. S. A., 95, 9761-9766.

19. Ross,W. and Gourse,R.L. (2005) Sequence-independent upstream DNA-alphaCTD interactions strongly stimulate Escherichia coli RNA polymerase-lacUV5 promoter association. Proc. Natl. Acad. Sci. U. S. A., 102, 291-296.

20. Cook,V.M . and DeHaseth,P.L. (2007) Strand opening-deficient Escherichia coli RNA polymerase facilitates investigation of closed complexes with promoter DNA: Effects of DNA sequence and temperature. J. Biol. Chem., 282, 21319-21326.

21. Feklistov,A. and Darst,S.A. (2011) Structural Basis for Promoter -10 Element Recognition by the Bacterial RNA Polymerase $\sigma$ Subunit. Cell, 147, 1257-1269.

22. Kubori,T. and Shimamoto,N. (1996) A Branched Pathway in the Early Stage of Transcription by Escherichia coli RNA Polymerase. J. Mol. Biol., 256, 449-457.

23. Ko,J. and Heyduk,T. (2014) Kinetics of promoter escape by bacterial RNA polymerase: effects of promoter contacts and transcription bubble collapse. Biochem. J., 463, 135-144.

24. Duchi,D., Bauer,D.L.V., Fernandez,L., Evans,G., Robb,N., Hwang,L.C., Gryte,K., Tomescu,A., Zawadzki,P., M orichaud,Z., et al. (2016) RNA Polymerase Pausing during Initial Transcription. Mol. Cell, 63, 939-950.

25. Henderson,K.L., Felth,L.C., M olzahn,C.M ., Shkel,I., Wang,S., Chhabra,M., Ruff,E.F., Bieter,L., Kraft, J.E. and Record,M.T. (2017) M echanism of transcription initiation and promoter escape by E. coli RNA polymerase. Proc. Natl. Acad. Sci. U. S. A., 114, E3032-E3040.

26. Hsu,L.M . (2002) Promoter clearance and escape in prokaryotes. Biochim. Biophys. Acta - Gene Struct. Expr., 1577, 191-207.

27. Susa,M ., Kubori,T. and Shimamoto,N. (2006) A pathway branching in transcription initiation in Escherichia coli. Mol. Microbiol., 59, 1807-1817.

28. Lerner,E., Chung,S.Y., Allen,B.L., Wang,S., Lee, ., Lu,S.W., Grimaud,L.W., Ingargiola,A., M ichalet,X., Alhadid,Y., Borukhov,S., Strick,T.R., Taatjes,D.J. and Weiss,S. (2016) Backtracked and paused transcription initiation intermediate of Escherichia coli RNA polymerase. Proc. Natl. Acad. Sci. U. S. A., 113, E6562-E6571.

29. Dulin,D., Bauer,D.L. V, M alinen,A.M ., Bakermans,J.J.W., Kaller,M ., M orichaud,Z., Petushkov,I., Depken,M ., Brodolin,K., Kulbachinskiy,A. and Kapanidis,A.N. (2018) Pausing controls branching between productive and non-productive pathways during initial transcription in bacteria. Nat. Commun., 9, 1478.

30. Sohn,B.K., Basu,U., Lee,S.W., Cho,H., Shen,J., Deshpande,A., Johnson,L.C., Das,K., Patel,S.S. and $\mathrm{Kim}, \mathrm{H} .(2020)$ The dynamic landscape of transcription initiation in yeast mitochondria. Nat. Commun., 11, 1-12.

31. Svetlov,V. and Artsimovitch,I. (2015) Purification of bacterial RNA polymerase: Tools and protocols. In Bacterial Transcriptional Control: M ethods and Protocols. Springer New York, pp. 13-29.

32. Belogurov,G.A., Vassylyeva,M .N., Svetlov,V., Klyuyev,S., Grishin,N. V., Vassylyev,D.G.G. and Artsimovitch,I. (2007) Structural Basis for Converting a General Transcription Factor into an Operon-Specific Virulence Regulator. M ol. Cell, 26, 117-129. 
bioRxiv preprint doi: https://doi org/10.1101/2021.03.27.437306; this version posted March 28,2021 . The copyright holder for this preprint (which was not certified by peer review) is the author/funder, who has granted bioRxiv a license to display the preprint in perpetuity. It is made available under aCC-BY-NC-ND 4.0 International license.

33. Turtola,M . and Belogurov,G.A. (2016) NusG inhibits RNA polymerase backtracking by stabilizing the minimal transcription bubble. Elife, 5:e18096.

34. Kulbachinskiy,A. and Mustaev,A. (2006) Region 3.2 of the $\sigma$ subunit contributes to the binding of the $3^{\prime}$-initiating nucleotide in the RNA polymerase active center and facilitates promoter clearance during initiation. J. Biol. Chem., 281, 18273-18276.

35. Holden,S.J., Uphoff,S., Hohlbein,J., Yadin,D., Le Reste,L., Britton,O.J. and Kapanidis,A.N. (2010) Defining the limits of single-molecule FRET resolution in TIRF microscopy. Biophys. J., 99, 31023111.

36. Kapanidis,A.N., Lee,N.K., Laurence,T.A., Doose,S., Margeat,E. and Weiss,S. (2004) Fluorescenceaided molecule sorting: Analysis of structure and interactions by alternating-laser excitation of single molecules. Proc. Natl. Acad. Sci. U. S. A., 101, 8936-8941.

37. Ha,T., Enderle,T., Ogletree,D.F., Chemla,D.S., Selvin,P.R. and Weiss,S. (1996) Probing the interaction between two single molecules: Fluorescence resonance energy transfer between a single donor and a single acceptor. Proc. Natl. Acad. Sci. U. S. A., 93, 6264-6268.

38. Van De Meent,J.W., Bronson,J.E., Wiggins,C.H. and Gonzalez,R.L. (2014) Empirical Bayes methods enable advanced population-level analyses of single-molecule FRET experiments. Biophys. J., 106, 1327-1337.

39. Dulin,D., Cui,T.J., Cnossen,J., Docter,M .W., Lipfert,J . and Dekker,N.H. (2015) High SpatiotemporalResolution Magnetic Tweezers: Calibration and Applications for DNA Dynamics. Biophys. J., 109, 2113-2125.

40. M cKinney,S.A., J00,C. and Ha,T. (2006) Analysis of single-molecule FRET trajectories using hidden Markov modeling. Biophys. J., 91, 1941-1951.

41. Kapanidis,A.N., M argeat,E., Ho,S.O., Kortkhonjia,E., Weiss,S. and Ebright,R.H. (2006) Initial transcription by RNA polymerase proceeds through a DNA-scrunching mechanism. Science, 314, 1144-1147.

42. Robb,N.C., Cordes,T., Hwang,L.C., Gryte,K., Duchi,D., Craggs,T.D., Santoso,Y., Weiss,S., Ebright,R.H. and Kapanidis,A.N. (2013) The Transcription Bubble of the RNA Polymerase-Promoter Open Complex Exhibits Conformational Heterogeneity and Millisecond-Scale Dynamics: Implications for Transcription Start-Site Selection. J. Mol. Biol., 425, 875-885.

43. Duchi,D., Gryte,K., Robb,N.C., M orichaud,Z., Sheppard,C., Brodolin,K., Wigneshweraraj,S. and Kapanidis,A.N. (2018) Conformational heterogeneity and bubble dynamics in single bacterial transcription initiation complexes. Nucleic Acids Res., 46, 677-688.

44. Clopper,C.J. and Pearson,E.S. (1934) The use of confidence or fiducial limits illustratedin the case of binomial. Biometrika, 26, 404-413.

45. Belogurov,G.A., Vassylyeva,M .N., Sevostyanova,A., Appleman,J.R., Xiang,A.X., Lira,R., Webber,S.E., Klyuyev,S., Nudler,E., Artsimovitch,I. and Vassylyev,D.G. (2009) Transcription inactivation through local refolding of the RNA polymerase structure. Nature, 457, 332-335.

46. Feklistov,A., Bae,B., Hauver,J ., Lass-Napiorkowska,A., Kalesse,M ., Glaus,F., Altmann,K.-H., Heyduk,T., Landick,R. and Darst,S.A. (2017) RNA polymerase motions during promoter melting. Science, 356, 863-866.

47. Winkelman,J.T., Vvedenskaya,I.O., Zhang,Y., Zhang,Y., Bird,J.G., Taylor,D.M ., Gourse,R.L., Ebright,R.H. and Nickels,B.E. (2016) M ultiplexed protein-DNA cross-linking: Scrunching in transcription start site selection. Science, 351, 1090-1093.

48. Estrem,S.T., Ross,W., Gaal,T., Chen,Z.W., Niu,W., Ebright,R.H. and Gourse,R.L. (1999) Bacterial promoter architecture: subsite structure of UP elements and interactions with the carboxyterminal domain of the RNA polymerase alpha subunit. Genes Dev., 13, 2134-2147.

49. Stumper,S.K., Ravi,H., Friedman,L.J., M ooney,R.A., Corrêa,I.R., Gershenson,A., Landick,R. and Gelles,J . (2019) Delayed inhibition mechanism for secondary channel factor regulation of 
bioRxiv preprint doi: https://doi. org/10.1101/2021.03.27.437306; this version posted March 28, 2021. The copyright holder for this preprint (which was not certified by peer review) is the author/funder, who has granted bioRxiv a license to display the preprint in perpetuity. It is made available under aCC-BY-NC-ND 4.0 International license.

ribosomal RNA transcription. Elife, 8:e40576.

50. Martell,D.J., Joshi,C.P., Gaballa,A., Santiago,A.G., Chen,T.Y., Jung,W., Helmann,J.D. and Chen,P. (2015) Metalloregulator CueR biases RNA polymerase's kinetic sampling of dead-end or open complex to repress or activate transcription. Proc. Natl. Acad. Sci. U. S. A., 112, 13467-13472.

\section{Figure captions}

Figure 1. Single-molecule FRET method to monitor the RNAP-promoter open complex formation in real-time. (A) E. coli RNAP- $\sigma^{70}$ holoenzyme is immobilised on the PEGylated microscope coverslip using biotinylated anti-His-tag-antibody. lacCONS+2 promoter, which is labelled with a donor fluorophore (D, Cy3B) at non-template DNA position - 15 and an acceptor fluorophore (A, ATT0647N) at template DNA position +15 , is added to the reaction buffer. The promoter binds to the RNAP and becomes visible on the coverslip surface. The initial RNAP-promoter closed complex isomerises to the open complex, which decreases the distance between the -15 and +15 dyes and increases the FRET. (B) Schematic microscope field-of-view before and after promoter addition to the reaction buffer. Data on the DD (donor excitation-donor emission) and AA (acceptor excitation-acceptor emission) channels is used to identify the RNAP-promoter complexes containing both the Cy3B and ATT0647N dyes. These molecules are highlighted with yellow circles. (C) Schematic single-molecule trajectory showing promoter binding to the RNAP and subsequent isomerisation to the open complex state. Abrupt increase in the Cy3B and ATT0647N fluorescence intensities defines the moment of promoter binding. The increase in the FRET from the low level to the intermediate level defines the moment of open complex formation. (D) Two experimental trajectories show promoter binding and open complex formation. DA indicates the signal on the donor excitation-acceptor emission channel.

Figure 2. Rate of $\mathrm{RP}_{0}$ formation. (A) Schematic representation of the real-time $\mathrm{RP}_{0}$ formation experiment. The promoter has donor and acceptor labels at positions -15 and +15 , respectively. (B) Example trajectory on the left demonstrates promoter binding to the surface-immobilised RNAP and the formation of RPc complex at $16.6 \mathrm{~s}$. The RPc isomerises to RPo complex at $17.2 \mathrm{~s}$. Another example trajectory of real-time $\mathrm{RP}_{0}$ complex formation is shown on the right. Dwell-times in the $\mathrm{RP}_{\mathrm{C}}$ state were fit to mono-exponential function to obtain the rate constant of $\mathrm{RP}_{0}$ complex formation (C) on the long dsLC2 promoter, (D) long pre-melted LC2 promoter and (E) short pre-melted LC2 promoter.

Figure 3. Intermediate on the $\mathrm{RP}_{0}$ complex formation pathway. (A) Example trajectories demonstrate the presence of an intermediate, $\mathrm{RP}_{i}$ complex, on the pathway from $\mathrm{RP}_{\mathrm{c}}$ to $\mathrm{RP}_{0}$ complex. The trajectory was fit to three state $H M M$. (B) $E^{*}$ histograms for the $\mathrm{RP}_{c}, \mathrm{RP}_{i}$ and $\mathrm{RP}_{0}$ states were extracted from the HM M segmented trajectories. The $E^{*}$ distributions were fit Equation 2. Data from different promoter versions was pooled. (C) E* histogram of the RNAP-promoter complexes formed in the presence of $100 \mu \mathrm{M}$ M yx inhibitor. The complexes were imaged $\sim 5 \mathrm{~min}$ after their initial formation on the coverslip surface. $E^{*}$ distribution was fit to Equation 2. 
bioRxiv preprint doi: https://doi. org/10.1101/2021.03.27.437306; this version posted March 28, 2021. The copyright holder for this preprint (which was not certified by peer review) is the author/funder, who has granted bioRxiv a license to display the preprint in perpetuity. It is made available under aCC-BY-NC-ND 4.0 International license.

Figure 4. Parallel formation of static and dynamic RPo's. (A) Example trajectories demonstrating the formation of static RPo. (B) Example trajectories demonstrating the formation of dynamic RPo. The static population represents $73 \%(\mathrm{~N}=107)$ of the nascent $\mathrm{RP}_{0}$ complexes, whereas the dynamic population represents $27 \%$ of the complexes $(N=40)$. (C) The abundance of static and dynamic $\mathrm{RP}_{0}$ 's is shown separately following the initial bubble opening either via 2-state (grey bars) or 3-state (pink) mechanisms. Exact 95\% binomial confidence intervals are shown. (D) E* histogram of dynamic $\mathrm{RP}_{\mathrm{o}}$ 's. The complexes were imaged $\sim 5$ min after their initial formation on the coverslip surface $(\mathrm{N}=$ 211 molecules). The $E^{*}$ distributions were fit using Equation 2.

Figure 5. Effect of RNAP cleft loop deletions on the reaction pathway branching and transcription bubble kinetics. (A) The position of deleted lid loop (LL), rudder loop (RL) and gate loop (GL) are shown in the cryo-EM model of E.coli RPo (PDB: 6psw, (10)). $\alpha, \beta$ and $\omega$ RNAP subunits and TraR transcription factor are omitted for clarity. ntDNA and tDNA are shown in dark and light grey, respectively. Blue sphere is the active site $\mathrm{Mg}^{2+}$ ion. (B) The $\mathrm{RP}_{0}$ complexes were classified as static or dynamic based on the 2-state HM M fit of the FRET trajectories. (C) The relative amounts of static and dynamic RPo. Error bar: exact $95 \%$ binomial $\mathrm{Cl}$. WT, $\mathrm{N}=212$ molecules; $\Delta \mathrm{RL}, \mathrm{N}=206 ; \Delta \mathrm{GL}, \mathrm{N}=136$; $\Delta \mathrm{LL}, \mathrm{N}=115$. (D) Dwell time distributions of the $\mathrm{RP}_{0}$ state within the dynamic RPo population were fit to mono-exponential equation. (E) The lifetime of $\mathrm{RP}_{0}$ state was obtained from the dwell distributions in panel D. Error bars are 1 SE extracted from the fit. (F) Dwell time distributions of the $\mathrm{RP}_{\text {Iso }}$ state within the dynamic $R P_{0}$ population were fit to mono-exponential decay equation. $(\mathrm{G})$ The lifetime of RPIso state was obtained from the dwell distributions in panel F. Error bars are $1 \mathrm{SE}$ extracted from the fit.

Figure 6. A working model for the $\mathrm{RP}_{0}$ complex formation mechanism. The reaction pathway from the promoter binding to the RPo complex is branched in two separate steps. The first branching is hypothesised to depend on a mobile RNAP element, which can be either in an active or inactive conformation (green and red flaps, respectively). The inactive conformation blocks the loading of the tDNA strand into the active site cleft, resulting the formation of intermediate $\mathrm{RP}_{\mathrm{i}}$. The isomerisation of the mobile element to the active conformation clears the block and allows progress from $\mathrm{RP}_{i}$ to $\mathrm{RP}_{\mathrm{O}}$. The second branching is related to the stability of the RNAP-template DNA interaction in the active site cleft. In $\sim 15 \%$ of the $\mathrm{RP}_{0}$ complexes, the interaction is weak, allowing continuous dynamic movement of the template DNA and thus the downstream DNA. Because stable and dynamics RPo complexes formed both from $\mathrm{RP}_{\mathrm{cl}}$ and $\mathrm{RP}_{i}$, we assume that these pathways merge before the next branching step leading to the stable and dynamics RPo's. Green vs red pins depict tight and loose interactions between the tDNA and the RNAP, respectively. The numeration $(1,2$ and 3$)$ indicates the key steps in the mechanism that define the rate and efficiency of RPo complex formation and that may be modulated by the promoter sequence and transcription regulators. 


\section{Figure 1}

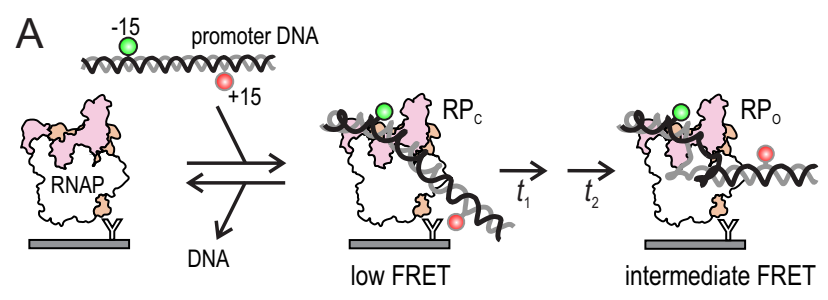

B
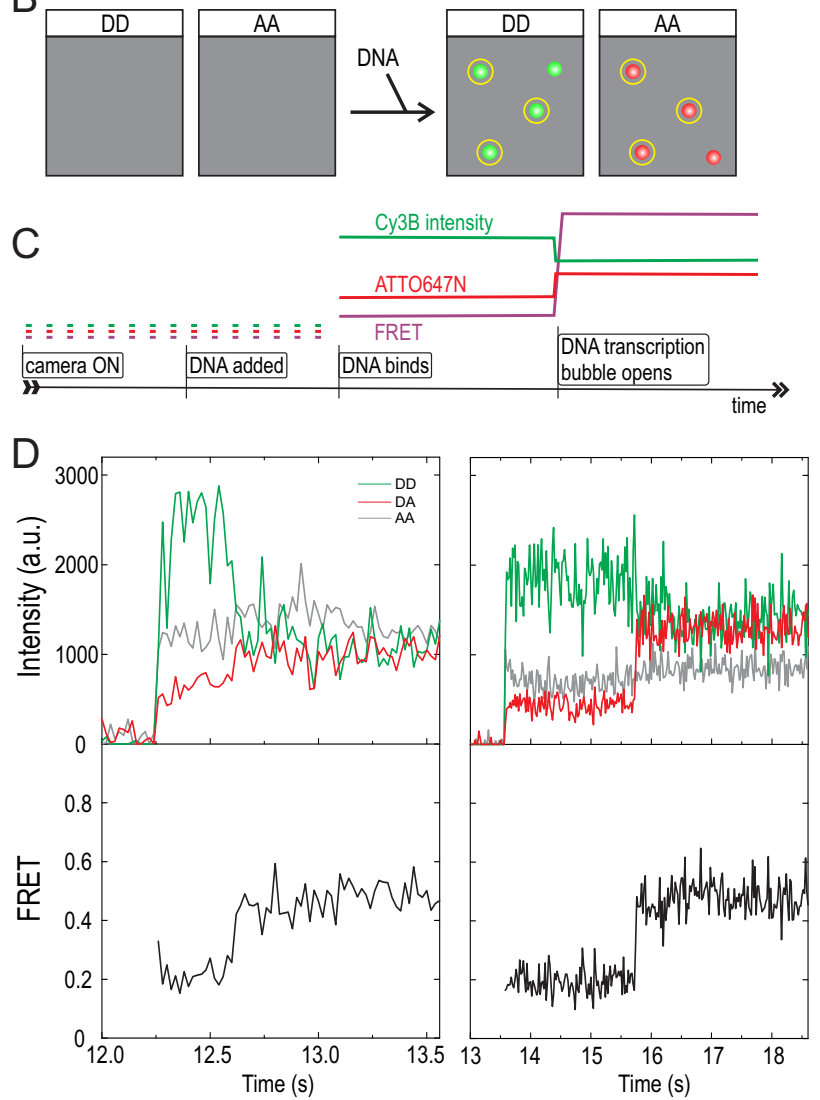


\section{Figure 2}

A romponas

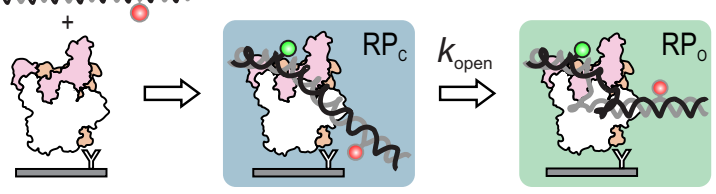

B
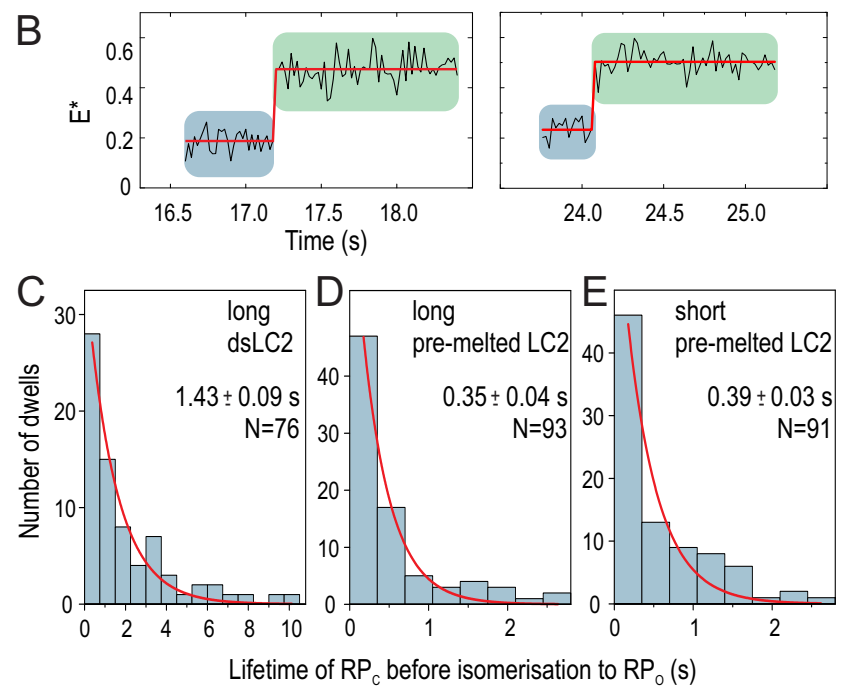
bioRxiv preprint doi: https://doi.org/10.1101/2021.03.27.437306; this version posted March 28, 2021. The copyright holder for this preprint (which was not certified by peer review) is the author/funder, who has granted bioRxiv a license to display the preprint in perpetuity. It is made available under aCC-BY-NC-ND 4.0 International license.

\section{Figure 3}
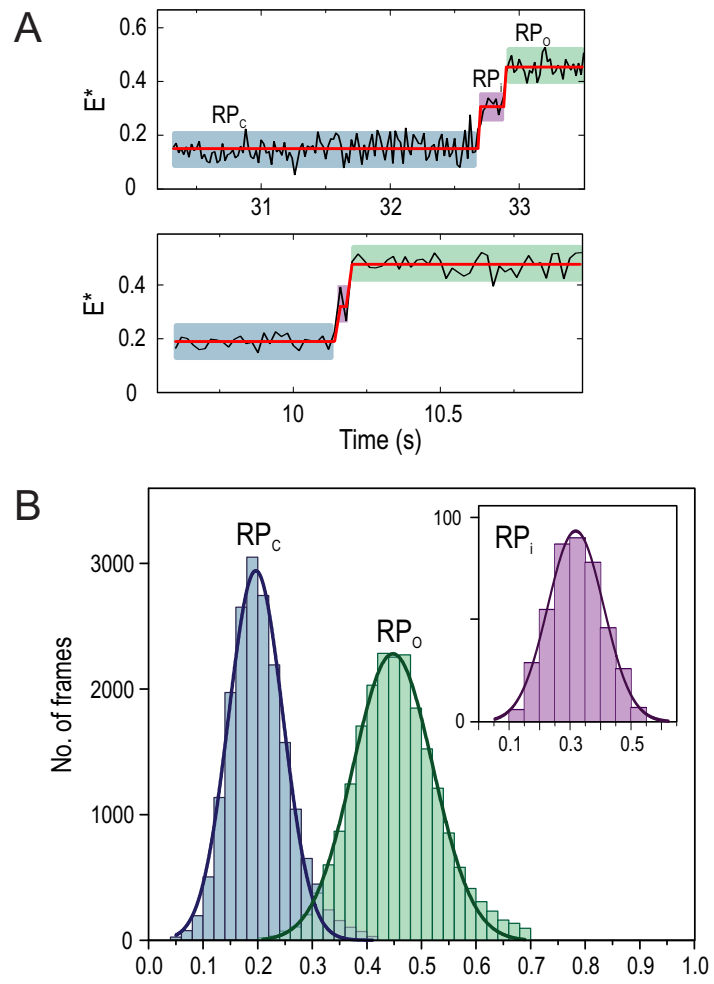

$E^{*}$

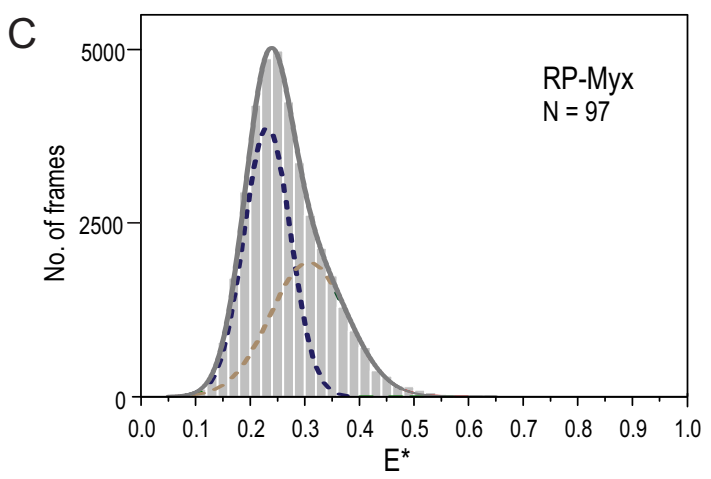


Figure 4:
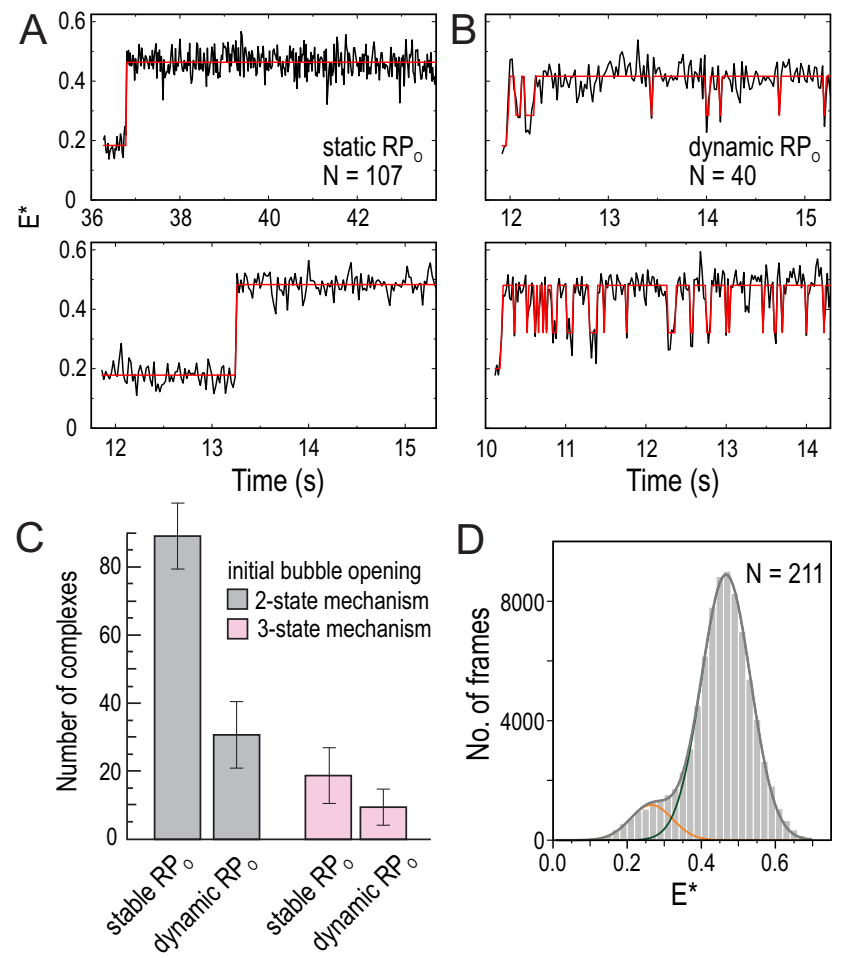
bioRxiv preprint doi: https://doi.org/10.1101/2021.03.27.437306; this version posted March 28, 2021. The copyright holder for this preprint (which was not certified by peer review) is the author/funder, who has granted bioRxiv a license to display the preprint in perpetuity. It is made available under aCC-BY-NC-ND 4.0 International license.

\section{Figure 5:}

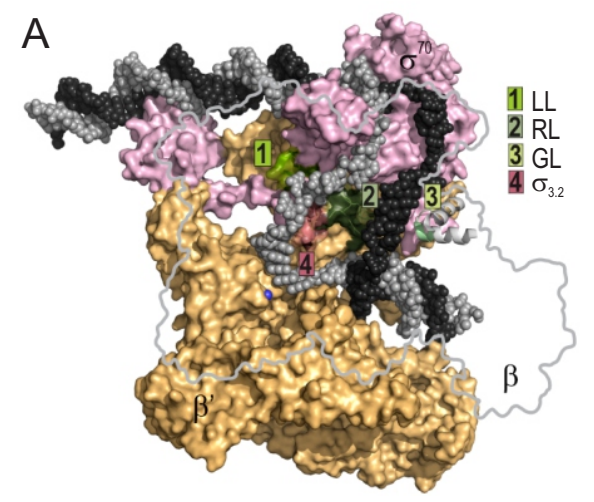

B

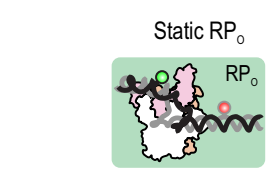

vS.

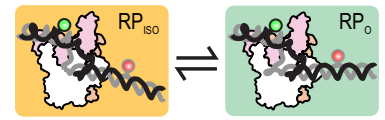

Dynamic RP
C

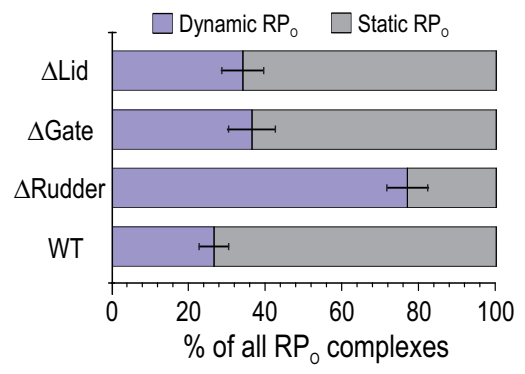

G
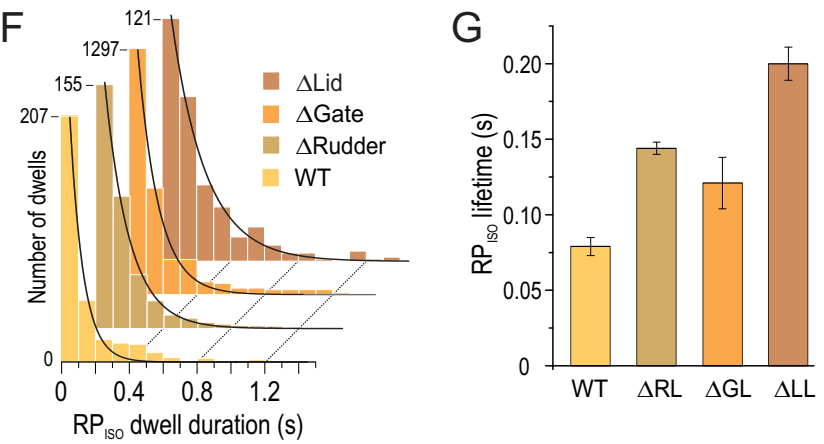

E

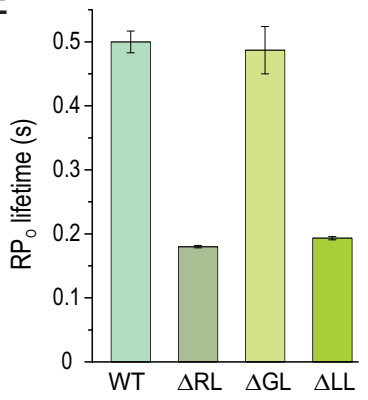

$\mathrm{RP}_{0}$ dwell duration (s) 


\section{Figure 6}

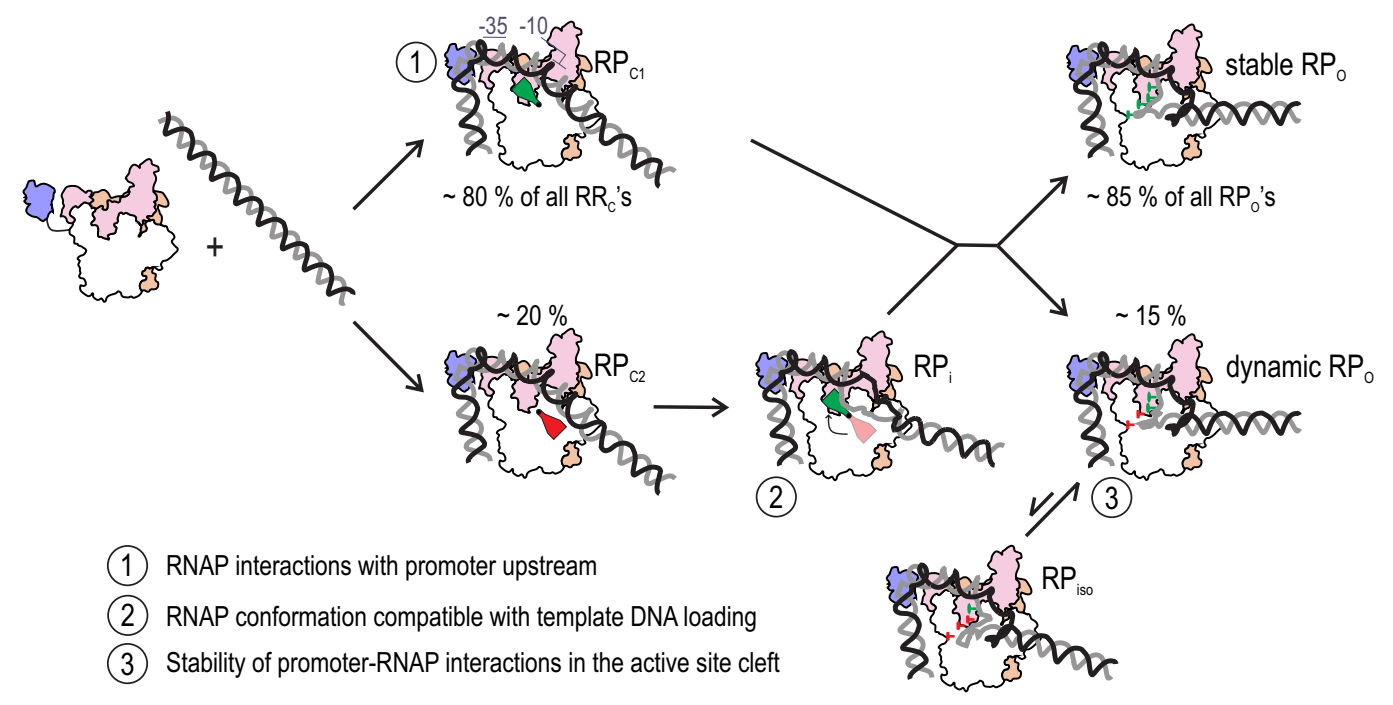

